\title{
Molecular Identification of Trypanosoma theileri and Biology of Trypanosomes
}

\author{
Tewodros Fentahun*11 and Jan Paeshuyse ${ }^{2}$ \\ ${ }^{I}$ Department of Veterinary Biomedical Sciences, College of Veterinary Medicine and Animal Sciences, University of Gondar, P.O.Box 196, Gondar, Ethiopia \\ ${ }^{2}$ KU Leuven, Faculty of Bioscience Engineering, Kasteelpark Arenberg 30 - bus 24723001, Leuven, Belgium \\ *Corresponding author's Email: tedyvet@gmail.com ; (DORCiD: 0000-0002-2955-5638
}

\begin{abstract}
Trypanosoma theileri (T. theileri) is a non-pathogenic, cosmopolitan, and commensal protozoa of cattle. The main objective of the current study was to investigate the biology and feasibility of $T$. theileri as a model candidate for the discovery of a novel drug. In the present study, the isolates of $T$. theileri obtained from the Institute of Tropical Medicine (ITM) in SDM 79 were cultivated at $26^{\circ} \mathrm{C}$. Eight experiments with different inoculum and different times were grown. The growth curve was plotted to check the growth trends. The doubling time in the logarithmic phase was determined to be 17.43 hours. In addition, an experimental infection was done on a 3-month-old Holstein Friesian calf to isolate the blood-streaming shape; however, it was not successful after the blood buffy coat smear and PBMC culture in RPMI 1640 and HMI 9. Furthermore, the viability was determined by quantitative colorimetric Resazurin assay in 96-well fluorescence Microplates containing 0.4 to $2.4 \mathrm{mM}$ of Resazurin. On the other hand, the response to Pentamidine (1-100 ng/mL) showed a strong negative correlation between the fluorescence signal and the highest Pentamidine concentration. $\mathrm{IC}_{50}$ was $9.25 \mathrm{ng} / \mathrm{mL}$. Genomic DNA was extracted using the phenolchloroform method. The gradient PCR amplification using T. theileri specific PCR (Tth625-PCR) primers was detected at 465 base pair (bp). In addition, the full-length $18 \mathrm{~S}$ rDNA sequence was detected at $730 \mathrm{bp}$. In the silico analysis using common anti-trypanosome drug targets, no significant similarity could be found on either the DNA or the protein level. Nevertheless, homologous sequences have been identified among the drug targets for Ornithine decarboxylase. Therefore, the analysis might show the possibility of using T. theileri as a model for the search of new drugs once they have entire genome sequences. Analysis of the whole genome and transcriptome indicated a phylogenetic relationship between T. theileri and other pathogenic trypanosomes which can be the basis for novel drug development.
\end{abstract}

Keywords: Drug model, Novel drug, PCR, Resazurin, SDM 79, Trypanosoma theileri

\section{INTRODUCTION}

The trypanosomatid parasites cause one of the most notorious human and animal trypanosomiasis in all parts of Africa and South America. Even if trypanosomes are the main cause of diseases in humans (sleeping sickness) and animals (Nagana), many other species are not pathogenic (Mott et al., 2011). Such pathogenic trypanosomatids occur globally and infect a large number of hosts. Among these, Trypanosoma theileri (T. theileri ) is ubiquitous, 'truly cosmopolitan' cattle protozoan commensal found worldwide (Mott et al., 2011 and Lee et al., 2013).

Natural infections could be found in all age groups of cattle although they are rare in cattle younger than one year old. Neither its life cycle nor its host relationship is fully understood in the mammalian host. The main vector responsible for the transmission of the parasite is Tabanidae. However, ticks including Hyalomma anatolicum and Boophilus microplus were also later reported as vectors (Latif et al., 2004). Hence, T. theileri is typically characterized by a stercorarian type of transmission (Latif et al., 2004). After ingesting infected blood, trypanosomes develop in the vector's hindgut. The infection is then transmitted to new hosts through fecal contamination of the mucus membrane or abrasions of the skin (Lukes, 2009). In the newly infected host, the epimastigotes multiply in the bloodstream by binary fission. Besides epimastigotes and large trypomastigotes in the peripheral blood, flagellates have also been found in extravascular sites of lymph nodes, kidneys, spleen, and brain (Braun et al., 2002).

In order to isolate pathogenic African Trypanosomes, a kit called KIVI (Kit for In Vitro Isolation of trypanosome) was designed (Aerts et al., 1992). Similarly, Verloo et al. (2000) proved that this kit can be used as an excellent device for isolating T. theileri with much higher sensitivity than the Roswell Park Memorial Institute (RPMI) medium. On the other hand, there was evidence that the growth of $T$. theileri on the RPMI medium could be easily confirmed (Lee et al., 2013). Many trypanocidal drugs are available in the market. Among these drugs, pentamidine, diminazene aceturate (Berenil), isometamidium chloride (Samorin), and ethidium bromide are important anti-trypanosomal drugs (Shapiro and Englund, 1990).

High-Throughput Screening (HTS) and virtual screening are used as a standard means in drug discovery to identify novel lead compounds that target a biomolecule of interest. However, the latter is considered a cost-effective means 
(Ekins et al., 2007; Fatumo et al., 2013). Editing of trypanosomatid RNA could be used to identify the drug target for protozoal parasites that cause diseases, such as trypanosomiasis. Amaro et al. (2008) reported that RNA-Editing Lgase-1 (REL-1) could be used as drug-like inhibitors of a key enzyme in the editing machine. The identification of inhibitors was done through a strategy employing molecular dynamics to account for protein flexibility (Amaro et al., 2008). New parasitic inhibitors had been identified due to the availability of an automated approach to high content microscopy (Alonso-Padilla and Rodriguez, 2014).

For better pharmacology hypotheses and tests, the development of computational (In Silico) methods plays a significant role. This methodology comprises pharmacophores, databases, quantitative structure-activity relationships, homology models, and other molecular modeling approaches, machine learning, network analysis tools, and data analysis tools using a computer.

Although T. theileri was not naturally pathogenic, it can cause disease in stressed cattle. Moreover, little is known about $T$. theileri. Recently, however, it has become an area of interest and is viewed as a tool and a vector for treating pathogenic microorganisms, particularly protozoan parasites (Mott et al., 2011). Furthermore, the mixed infection of $T$. theileri cause pathogenic trypanosome on the same host (cattle), and the presence of homologous sequences with specific sequences of anti-trypanosomal drug targets from pathogenic trypanosomes could lead to the use of this parasite ( $T$. theileri) as a model candidate for the development of new drugs for the treatment of pathogenic trypanosomes. To this end, the basics of the parasite should be studied to manipulate the parasite as a tool to combat pathogenic trypanosomes. Furthermore, little is known about the biology, cell growth pattern, doubling time, and viability of the parasite. There is little convincing data to determine whether $T$. theileri could be used as a model for discovering new drugs for the treatment of pathogenic trypanosomiasis.

The general aim of the present research was to provide fundamental insights into the biology of $T$. theileri to verify its feasibility as a model organism for the discovery of the new drug. The specific objectives were cultivation of $T$. theileri both in vitro and in vivo, comparing and analyzing the growth pattern with others to check viability with Resazurin assay analysis and response to the drug, and determining the presence of homologous sequences between its genome and the specific target (conserved) sequence of anti-trypanosome drugs.

\section{MATERIALS AND METHODS}

\section{Ethical approval}

During the entire experimental period, the care and maintenance of the calf in its pen was performed based on the guidelines of the European Convention for the Protection of Vertebrate Animals used for Experimental and other Scientific Purposes. Furthermore, the experimental protocols were used after the approval by the Animal Research and Ethical Review Committee at the KU Leuven University (Permit No: P024/2017)

\section{Parasites and in vitro culture}

The sample used in the current study was T. theileri, kindly donated by the Diagnostic Parasitology Department of the Institute of Tropical Medicine, Belgium. These cryogenically preserved trypanosomes in culture were isolated from a small farm nearby Antwerp, Belgium by Verloo et al. (2000). Different growth media and conditions, under which other trypanosomes were grown in the institute, were assessed to determine the optimal conditions and favorable growth media for culturing the parasite. After identifying the appropriate medium (SDM 79) and the growth condition (at $26^{\circ} \mathrm{C}$, without $\mathrm{CO}_{2}$ ), the cryostablate was seeded (1: 10 ratio) and propagated three times with SDM 79 medium (BioConcept AMIMED company, Switzerland) in a cell culture flask $\left(25 \mathrm{~cm}^{2}\right.$, Thermo Scientific ${ }^{\mathrm{TM}}$ Nunc ${ }^{\mathrm{TM}}$ Cell Culture Flasks). It was counted daily with a hemocytometer and recorded in the logarithmic table. A growth curve was then plotted to determine the growth pattern. In addition, the minimum and the maximum number of cells in the eight-cell culture flasks (eight experiments) that could serve as a potential indicator of the logarithmic phase and considered for both the experimental infection and Resazurin assay development were stored. Moreover, T. theileri was sub-passaged every three days. Epimastigotes were harvested in the exponential growth phase. Epimastigoteswas were centrifuged (1500 rpm for 10 minutes to sediment, washed, and re-suspended with phosphate buffer saline $(\mathrm{PBS}, \mathrm{pH}=7.2)$ before inoculation to the experimental calf while it was being used for DNA extraction.

\section{Experimental animal and infection}

A Holstein Friesian calf (aged three months) was randomly selected from the zootechnical Centre, KU Leuven, Belgium. It was confirmed to be trypanosome-negative by taking the blood sample and smear and culture in HMI-9 medium. After confirmation, it was inoculated with the sub-cultured epimastigotes of T. theileri $\left(4.5 \times 10^{6} / \mathrm{mL}\right.$ to 7.3 $\times 10^{6} / \mathrm{mL}$ ), intravenously (IV) through the jugular vein in a volume of 5-9 mL. In addition to parenteral inoculation, the calf was orally drenched with the same amount of inoculation. The calf was monitored and examined for parasitemia for three consecutive weeks. Blood samples $(10 \mathrm{~mL})$ were collected using Ethylenediaminetetraacetic Acid (EDTA) coated 
vacutainer tubes. The samples were collected two times after experimental infection (every week after experimental infection). After the blood samples were transported to the Host-Pathogen Interaction Laboratory of KU Leuven, Belgium, the samples were examined for the presence of trypanosomes using the standard parasitological methods of the wet and thin blood smear (stained with Giemsa), PBMC, and buffy coat technique within two to three hours of sampling per day (Murray et al., 1977).

\section{The buffy coat/PBMCculture}

After extracting the buffy coat (Murray et al., 1977) and PBMC (Ficoll-Paque method), the buffy coat samples were transferred to two cell culture flasks $\left(25 \mathrm{~cm}^{2}\right.$, Thermo Scientific ${ }^{\text {TM }}$ Nunc ${ }^{\text {TM }}$ Cell Culture Flasks) containing HMI-9 medium and RPMI 1640 supplemented with 10\% fetal calf serum (FCS, Sigma) and 200 IU/mL of penicillin and $100 \mu \mathrm{g} / \mathrm{Ml}$ streptomycin (Invitrogen, Carlsbad, CA) according to Hirumi and Hirumi (1989). A ratio of 1:10 (1 ml of buffy coat sample to $10 \mathrm{ml}$ of the HMI-9 medium) was used. The inoculated cell culture flasks containing HMI-9 medium were then incubated at $37^{\circ} \mathrm{C}$ and exposed to $5 \% \mathrm{CO}_{2}$. The tests were checked daily under an inverted microscope at $40 \times$ magnification to monitor the progress of growth in both cell culture flasks inoculated for a maximum of two weeks.

\section{In vitro sensitivity assays (Resazurin assay)}

A reagent, Resazurine obtained from Sigma-Aldrich, was used as a quantitative colorimetric assay based on the oxidation (blue) and reduction (pink) indicators to measure T. theileri viability and its response to pentamidine. Resazurin stock solution (0.4 to $2.4 \mathrm{mM}$ ) was prepared in PBS withpH 7and filter-sterilized (Miriam et al., 2006).

\section{Optimization of Resazurin to Trypanosoma theileri viability}

To reduce the background signal for a better sensitivity assay and also to avoid light piping between wells, the Black Microtiter® 96-Well Fluorescence microplates were used. Cells ranging from $5.2 \times 10^{5} / \mathrm{mL}$ to $8.5 \times 10^{6} / \mathrm{mL}$ with a logarithmic phase were obtained after incubation in cell culture flasks at $26^{\circ} \mathrm{C}$ for 48 hours. Then, $120 \mu \mathrm{L}$ cells of $T$. theileri were removed from this cell culture flask into wells of Microtiter ${ }^{\circledR}$ 96-Well Fluorescence Microplates (Thermo Scientific) and incubated again at $26^{\circ} \mathrm{C}$ for 48 hours. After 48 hours of incubation, $20 \mu$ of different concentrations of Resazurin solution ( 0.4 to $2.4 \mathrm{mM}$ ) was added to each inoculum while an equivalent amount of SDM 79 medium was added for blank wells. The plates were returned to the incubator for 24 hours for optimal oxidation and reduction. The Fluorescence signal was read 1, 3, 5, 7, 18, and 24 hours after the addition of Resazurin by dual-wavelength using a GFP protocol-VICTOR ${ }^{\text {TM }}$ X Series Multi-label Plate Reader (Perkin Elmer Instruments Inc.) at $\kappa_{\text {exc }} 485$, and $\kappa_{\mathrm{em}} 535 \mathrm{~nm}$. A single micro-titer plate was used for three different concentrations of Resazurin per experiment. The background was subtracted from each reading. The experiments were performed three times and an average was taken.

\section{Standard curves}

Following incubating epimastigotes in the range of $1.3 \times 10^{6}$ to $5.3 \times 10^{6}$ epimastigotes $/ \mathrm{mL}$ for 48 hours, $120 \mu \mathrm{L}$ of epimastigotes $/ \mathrm{mL}$ per well were seeded to a 96 well microtiter plate for further 48 hours of incubation at $26^{\circ} \mathrm{C}$. Then, 20 $\mu \mathrm{L}$ of $2.4 \mathrm{mM}$ Resazurin was added followed by fluorescence signal reading after 7 hours of incubation. This procedure was performed twice in all three times.

\section{Drugs sensitivity assay}

Pentamidine was dissolved in concentrations from1.0 to $80 \mathrm{ng} / \mathrm{ml}$. In each wellofCostarTM 96-well microtitre plates, $120 \mu \mathrm{l}$ of epimastigotes of $T$. theileri in the logarithmic phase $\left(1.4-5.3 \times 10^{6} / \mathrm{mL}\right)$ was seeded with $20 \mu \mathrm{L}$ of different concentrations of pentamidine (1.0 to $80 \mathrm{ng} / \mathrm{ml})$. Three drug concentrations were tested per plate (column 1-3 with $1.0 \mathrm{ng} / \mathrm{ml}$, column 4-6 with $40 \mathrm{ng} / \mathrm{ml}$, column 7-9 with $80 \mathrm{ng} / \mathrm{ml}$ pentamidine, column 10 without the drug, and column 11SDM 79 medium used as control medium). The plates were then incubated with pentamidine for 48 hours. The trypanosome density was counted with a hemocytometer up to 48 hours of incubation before the addition of Resazurin. Afterwards, the plates were incubated by adding a $20 \mu \mathrm{L}$ Resazurin to each well and incubated at $26^{\circ} \mathrm{C}$ for an additional seven hours. $\mathrm{IC}_{50}$ values were also calculated at concentrations $1-100 \mathrm{ng} / \mathrm{mL}$ using this assay and microscopic counting. Columns 1-10 were tested for drugs, column 11 was without the drug, and column 12 included only SDM 79 as the control medium.

\section{Data Evaluation and analysis}

The plate was read at an excitation wavelength of $485 \mathrm{~nm}$ and an emission wavelength of $535 \mathrm{~nm}$ in a fluorescence/microplate reader (GFP protocol-VICTOR ${ }^{\text {TM }}$ X Series Multi-label Plate Reader (PerkinElmer Instruments Inc.). The data were transferred into a graphics program (Excel) and analyzed using the GraphPad Prism 7.0. Descriptive 
statistics and Pearson $\mathrm{r}^{2}(\mathrm{r})$ correlation coefficient were also calculated. To measure the anti-epimastigotes activity (\%AE), the following formula according to Miriam et al. (2006) was used.

$$
\left.\mathbf{A E}(\%)=\frac{(\mathbf{G c}-\mathbf{G p})}{\mathbf{G c}} \times \mathbf{1 0 0} \quad \text { (Equation } 1\right)
$$

Where, Gc represents the mean number of parasites per milliliter in the control, and Gp shows the mean number of parasites per milliliter according to the different doses of drugs.

Furthermore, the doubling time was calculated based on the following equation used for T.b.brucei by Sykes and Avery (2009) and Melissa et al. (2009).

$\mathrm{TD}=(\mathrm{t} 2-\mathrm{t} 1) \frac{\log (2)}{\log (\mathrm{q} 2 / \mathrm{q} 1)}($ Equation 2$)$

Where, Td refers to doubling time (q1), $\mathrm{t} 1$ is the first quantity for the first time, and (q2) at the time (t2) denotes the second quantity at the second time.

\section{Genomic DNA extraction and PCR amplification}

A T. theileri culture in a high density of the logarithmic phase ranging from $3.6 \times 10^{6}$ cells $/ \mathrm{ml}$ to $7.8 \times 10^{6}$ epimastigotes $/ \mathrm{mL}$ was utilized to extract genomic DNA. Both the phenol-chloroform method and DNeasy®Blood and Tissue Kit (Qiagen, Hilden, Germany) were used. The concentration and purity of the DNA were determined with

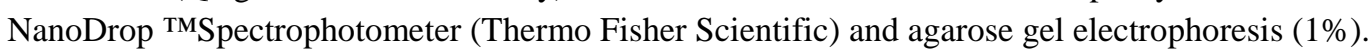

\section{DNeasy ${ }^{\circledR B l o o d}$ and tissue kit}

The genomic DNA extraction was conducted according to the protocol recommended by the manufacture Purification of Total DNA from Animal Blood or Cells (DNeasy 96 Protocol), DNeasy®Blood and tissue kit (Qiagen, Hilden, Germany).

\section{Phenol-chloroform method}

Cultivated $T$. theileri cells $\left(3.6 \times 10^{6}\right.$ cells $/ \mathrm{ml}$ to $7.8 \times 10^{6}$ cells $\left./ \mathrm{ml}\right)$ in $2 \mathrm{ml}$ Eppendorftubeswere lysed by centrifugation at $13000 \mathrm{rpm}$ for a minute. The supernatants were removed and $500 \mu \mathrm{L}$ of T10N150E10wereadded and mixed thoroughly by pipetting several times. The content was then centrifuged at $13000 \mathrm{rpm}$ for 10 minutes and the supernatant was removed, followed by the addition of500 $\mu \mathrm{L}$ of $\mathrm{T}_{10} \mathrm{~N}_{150} \mathrm{E}_{10}$. This step was repeated twice.

Eight hundred microliter of freshly prepared Glouton-Buffer (10mM Tris HCl, $10 \mathrm{mM}$ EDTA, 100mM NaCl, 10\% SDS, 3.9Mm DTT) were added and mixed well by pipetting up and down. It was then incubated at $65^{\circ} \mathrm{C}$ for one hour. Afterwards, $20 \mu \mathrm{l}$ of $10 \mu \mathrm{g} / \mathrm{mL}$ proteinase $\mathrm{K}$ was added and incubated at $56^{\circ} \mathrm{C}$ overnight.

An equal volume $(1000 \mu \mathrm{L})$ of phenol/chloroform/isoamyl alcohol in the ratio of 25:24:1 was added and mixed gently. After centrifuging at $13000 \mathrm{rpm}$ for 10minutes, the supernatant was transferred to a new tube. The same amount of phenol/chloroform was added to a new tube, mixed, and centrifuged as above-mentioned. The supernatants were transferred to a new tube again and the same amount of chloroform was added, mixed, and centrifuged as indicated above. The aqueous layer $(500 \mu \mathrm{l})$ was transferred to a new tube and mixed gently with $1166 \mu \mathrm{L} 100 \%$ Ethanol. The supernatants were removed after centrifugation at $13000 \mathrm{rpm}$ for 1 minute. The tubes were left open to dry DNA for 3 hours, then it was resuspended with $30 \mu \mathrm{L}$ of Mili-Q water.

\section{PCR amplification and gel electrophoresis}

Species-specific PCR identification was performed using the following primers in Table 1 as described by Rodrigues et al. (2003) and Lee et al. (2013). Amplification was conducted using $25 \mu \mathrm{L}$ reaction mixture with $200 \mathrm{ng}$ template DNA (genomic DNA), 2.5 IU (International Unit) TagDNA polymerase (Promega, U.S.A), 0.2 mM dNTP, PCR buffer, $1.5 \mathrm{mM} \mathrm{MgCl}_{2}$, (Promega, U.S.A), and $0.3 \mu \mathrm{M}$ of primer, according to the manufacturer's instructions. For gradient PCR Amplification, the procedure involved $95^{\circ} \mathrm{C}$ for 5 minutes, followed by 20 cycles of $94^{\circ} \mathrm{C}$ for 10 seconds, $53^{\circ} \mathrm{C}$ for 15 seconds, and $67^{\circ} \mathrm{C}$ for 1 minute, with a final extension at $72^{\circ} \mathrm{C}$ for 3 minutes.

Finally, PCR products were run on $1 \%$ agarose gel (Sigma) electrophoresis using $1 \times$ TBE buffer and stained with $7 \mu \mathrm{L}$ ethidium bromide in $50 \mathrm{~mL}$ agarose $(0.5 \mathrm{ng} / \mathrm{mL})$ and made visible using UV transillumination (Vilmar Lourmat).

Table 1. Primers used to detect Trypanosoma theileri

\begin{tabular}{cll}
\hline & Primer (Forward and Reverse) & Purpose \\
\hline 1 & $\begin{array}{l}\text { Tth625a (5'-CCG CTG GAG CTA AGA ATA GA-3') and } \\
\text { Tth625b (5'-AAT TGC ATA AAC ACA GCT CCC-3') }\end{array}$ & $\begin{array}{l}\text { For species-specific PCR amplification } \\
\text { (Tth625-PCR) }\end{array}$ \\
\hline & $\begin{array}{l}\text { Forward primer 18STnF2 (5'-CAA CGA TGA CAC CCA TGA ATT GGG GA-3') } \\
\text { and }\end{array}$ & $\begin{array}{l}\text { The full length 18S ribosomal DNA } \\
\text { sequence Analysis }\end{array}$ \\
& Reverse primer 18STnR3 (5'-TGC GCG ACC AAT AAT TGC AAT AC-3') & For single PCR amplification to anneal \\
& Kin1 reverse (5'- GCG TTC AAA GAT TGG GCA AT-3') and & $\begin{array}{l}\text { internal transcribed spacer of } \\
\text { ribosomal genes (ITS) sequence }\end{array}$ \\
\hline
\end{tabular}

Source: Rodrigues et al. (2003) and Lee et al.(2013) 


\section{In silico analysis by multiple sequence alignments}

Multiple Sequence Alignments (MSA) were conducted with commonly used anti-trypanosomal drug target sequences (Table 1) from pathogenic Trypanosoma species and T. Theileri genome/proteome using FFT in ExPASy tool, Switzerland (Rodrigues et al., 2003). In addition, phylogenetic trees were created to study the relationships between the different drug targets and the $T$. theileri genome/proteome, as well as between the drug target sequences.

\section{Risk analysis}

The T. theileri is a non-pathogenic parasite and does not cause disease in either livestock or humans. There is no biological hazard to the calf from parasite inoculation. Therefore, there are no biochemical hazards for the farm and environment when carrying out such an experiment.

\section{RESULTS}

\section{Growth medium and conditions}

Different types of cell culture media commonly used to culture other types of Trypanosoma in ITM were screened to assess the optimal and conducive conditions to culture T. theileri epimastigotes. Cryogenically preserved $2.5 \times 10^{6}$ epimastigotes $/ \mathrm{mL}$ were seeded into a cell culture flask $\left(25 \mathrm{~cm}^{2}\right.$, Thermo Scientific ${ }^{\mathrm{TM}}$ Nunc ${ }^{\mathrm{TM}}$ Cell Culture Flasks) in four different media and growth conditions (Figures 1 and 2). It was seeded at a 1:10 ratio and sub-passaged every three days for two consecutive weeks. Finally, the optimal conditions and favorable growth media for $T$. theileri epimastigotes were identified. As a result, significant growth of the T. theileri could be observed in SDM 79 at $26^{\circ} \mathrm{C}$ without $\mathrm{CO}_{2}$, and RPM'3I 1640 at $37^{\circ} \mathrm{C}$ with $5 \% \mathrm{CO}_{2}$ with $10 \%$ Fetal Calf Serum (FCS), as shown in Figures 1 and 2, respectively. However, relatively slower growth was observed for the later third day. On the other hand, there was a prominent growth in RPMI 1640 with 10 \% FCS than other serum types used (Figure 2).

\section{Growth pattern and doubling time}

After inoculation $\left(2.5 \times 10^{6}\right.$ epimastigotes $\left./ \mathrm{mL}\right)$ of T. theileri in eight flasks containing SDM 79 with $10 \%$ FCS, the growth pattern was determined by counting $10 \mu \mathrm{L}$ from each flask daily with a Haemocytometer. As indicated in Figure 3, maximum growth was observed on the sixth day in the entire eight-cell culture flask, except for the seventh experiment, which took place on the seventh day. The maximum number of epimastigotes that could be grown among the eight flasks was estimated to be $1.7 \times 10^{7} \mathrm{cells} / \mathrm{mL}$ (Experiment 2). The doubling time was calculated per day assuming they were in the logarithmic phase from the third to sixth day as indicated in Figure 3. Since there was a significant growth of the parasite in this period, from $3.2 \times 10^{4} \mathrm{cells} / \mathrm{mL}$, which was the lowest on the third day from the second experiment to the highest $1.3 \times 10^{7}$ cells $/ \mathrm{mL}$ from the same flask on the sixth day. The calculation was based on the manipulation of the doubling time equation used for T.b.brucei from Sykes and Avery(2009) and Melissa et al. (2009) as described in materials and methods. Therefore, the doubling time calculated in the logarithmic growth phase averaged 17.43 hours ( 0.73 day) for eight experiments.

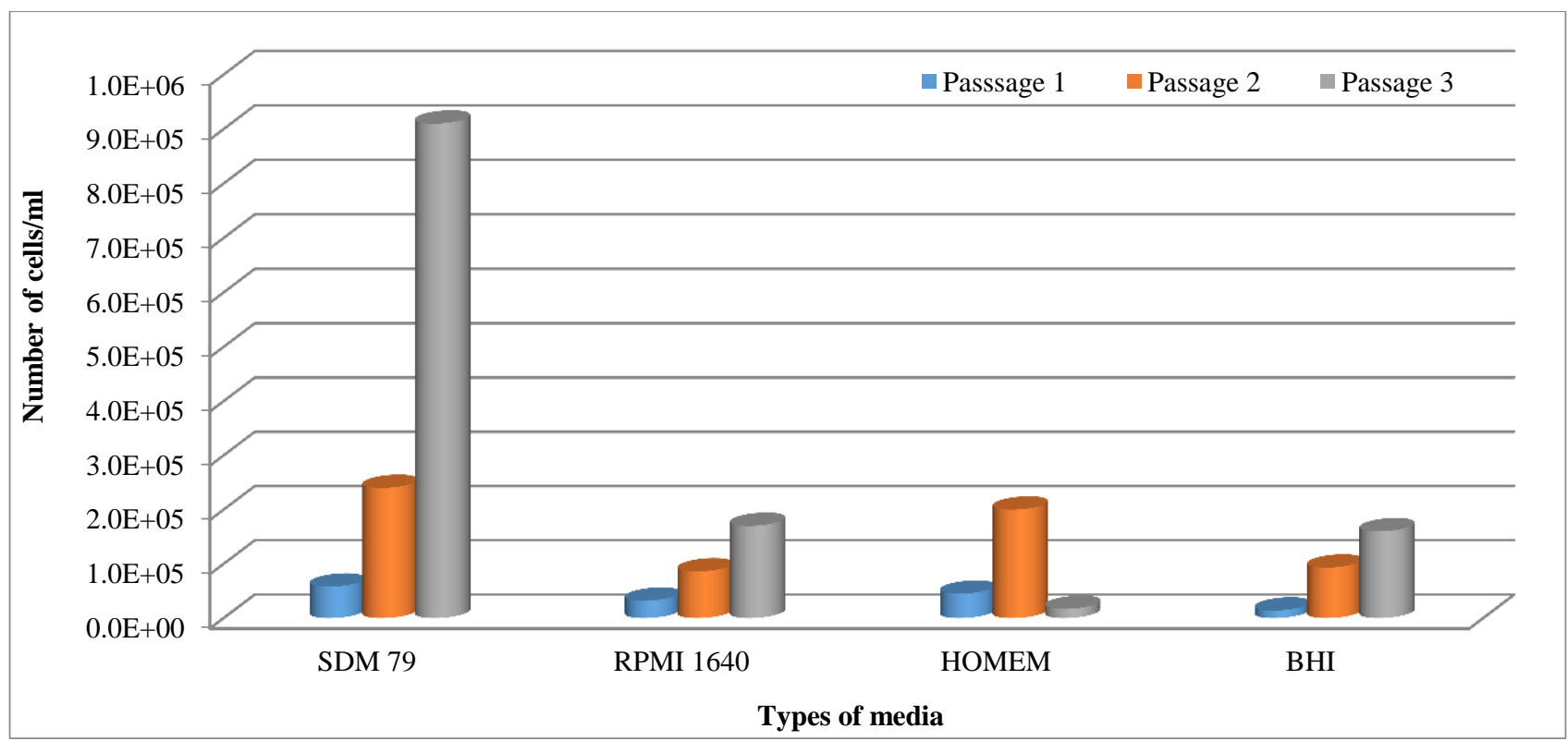

Figure 1. Growth of Trypanosoma theileri with various media at $26^{\circ} \mathrm{C}$ without $\mathrm{CO}_{2}$ in cell culture flasks. It was performed at the Institute of Tropical Medicine Antwerp, Belgium for two consecutive weeks 


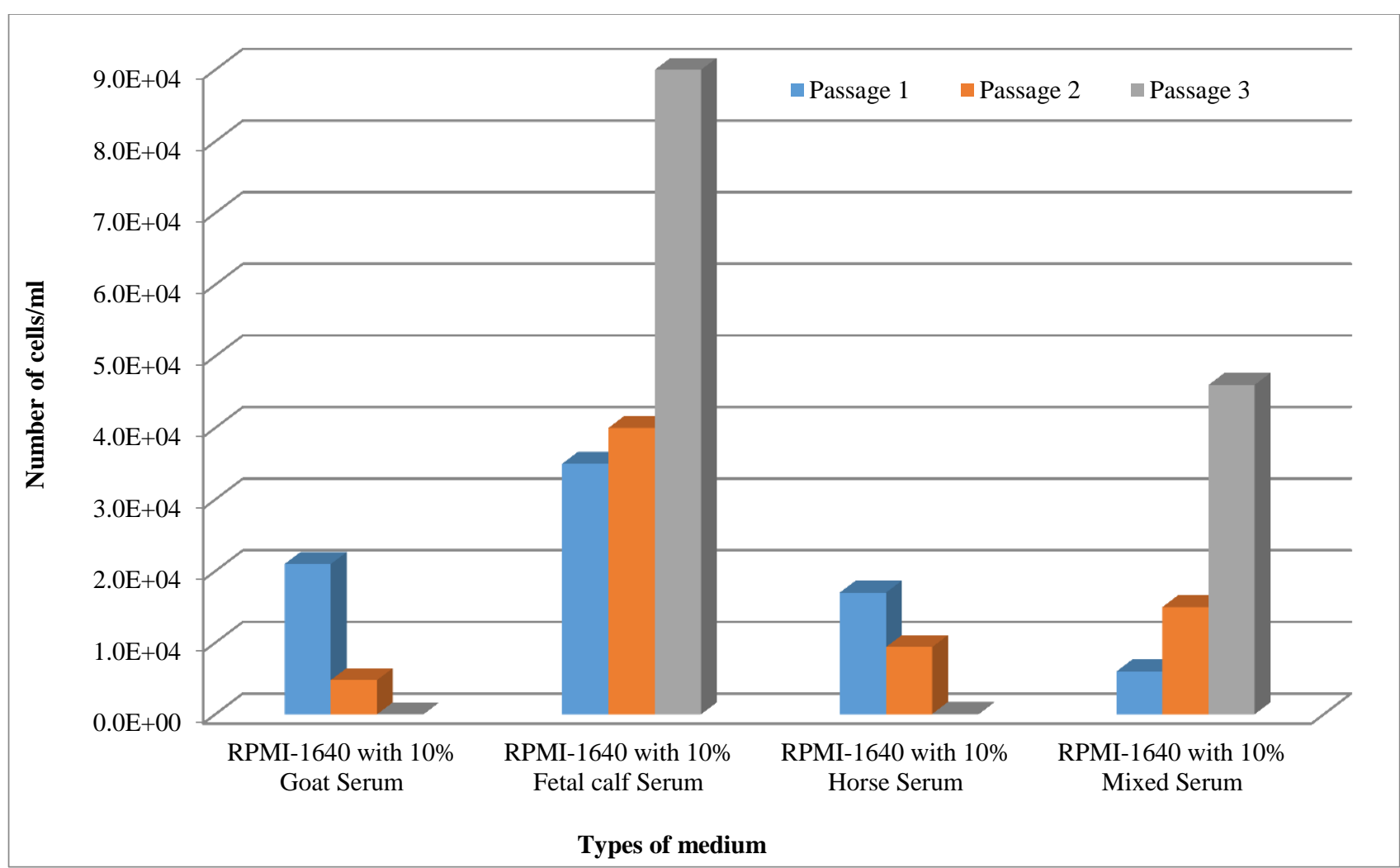

Figure 2. Growth of Trypanosoma theileri with RPMI 1640 in different serum types at $37^{\circ} \mathrm{C}$ with $5 \% \mathrm{CO}_{2}$ in cell culture flask at ITMor two weeks

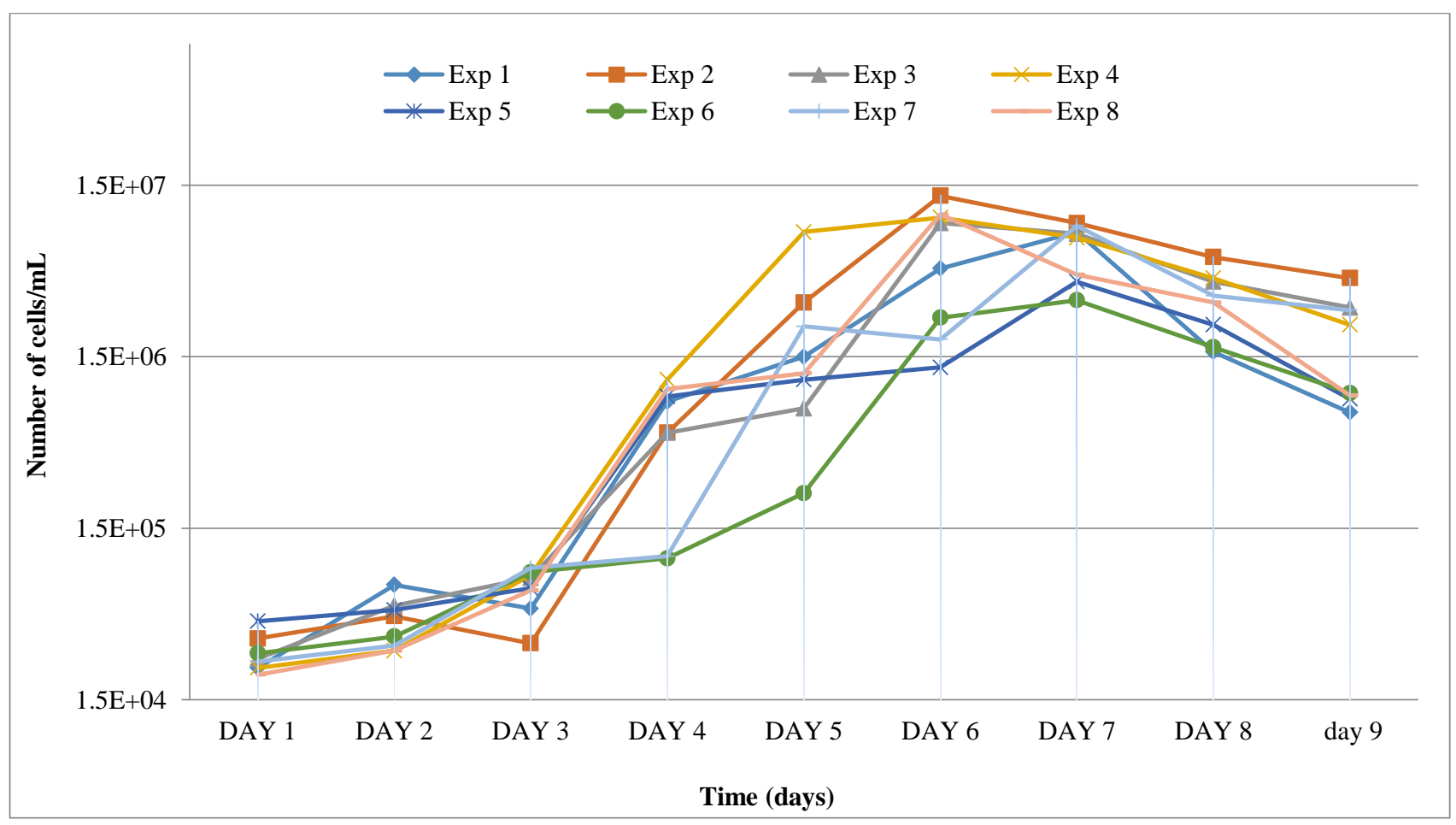

Figure 3. The growth pattern of Trypanosoma theileri in eight tissue culture flasks considered as experiments for nine days incubated in $\mathrm{SDM} 79$ at $26^{\circ} \mathrm{C}$ without $\mathrm{CO}_{2}$. Exp: Experiment

To assess the morphology and the relative difference between other stages, Giemsa and DAPIstains (4',6diamidino-2-phenylindole) were performed on slides. Some of the slides were stained at ITM and some others in the Host Interaction lab, KU Leuven, Belgium (Figure 4). 


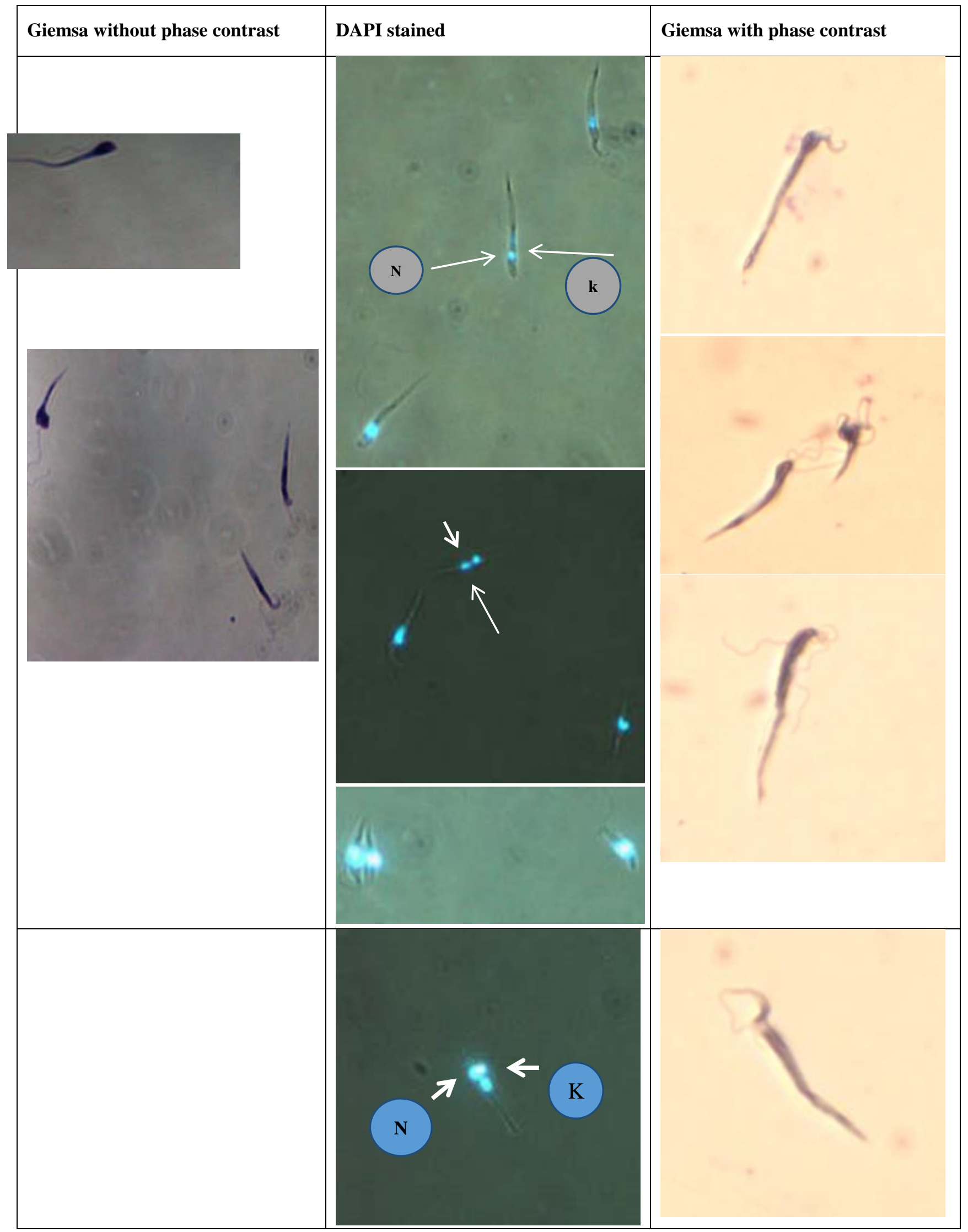

Figure 4. Light microscopy of Trypanosoma theileri epimastigotes cultured at $26^{\circ} \mathrm{C}$ (Giemsa and DAPI stained, $400 \times$ magnifications). A kinetoplast is anterior to the nucleus, unlike a trypomastigote which has a kinetoplast posterior to the nucleus. $\mathrm{N}$ : Nucleus, K: Kinetoplast.

\section{Resazurin assay}

After optimization, T. Theileri was grown in microtiter plates and reached the level to produce a detectable fluorescence signal by incubation with $20 \mu \mathrm{L}$ of each Resazurin solution. The magnitude of fluorescence increased remarkably up to7 hours, after which the fluorescence saturation occurred, particularly at $3.5 \times 10^{6}$ epimastigotes $/ \mathrm{mL}$, which had the highest density and then gradually decreased (Figure 5). 
A statistically significant difference in the fluorescence of Resazurin solution at three concentrations $(0.4 \mathrm{mM}$ to $2.4 \mathrm{mM}$ ) was observed $(\mathrm{p}<0.05)$ with an increase in the number of parasites and the incubation time $(7$ hours $)$ during the assay (Figures 5 and 6). There was a positive correlation ( $r=0.75$ to 0.925$)$ between the magnitude of fluorescence of various cell densities and the three Resazurin concentrations (Table 6). However, the growth declined from $3.5 \times 10^{6}$ to $7.9 \times 10^{6}$ epimastigotes $/ \mathrm{mL}$, which indicated that the epimastigote was reaching the stationary phase. Hence, the upper limit of the assay was a plating density of $3.5 \times 10^{6}$ epimastigotes $/ \mathrm{ml}$ (Figure5).

Trypanosoma theileri were seeded with $1.6 \times 10^{6}$ epimastigotes $/ \mathrm{ml}$, which resulted in a low level of fluorescence on the first reading (in the first hour after the addition of Resazurin) at the beginning of the assay process. Then, it gradually increased and a maximum signal was received seventh hours after adding Resazurin, and then significantly declined until the last reading (24 hours after adding Resazurin, Figure 6). Overall, the fluorescence signal of Resazurin solutions had a positive correlation ( $r=0.75$ to 0.925$)$ with cell density and incubation time. There was a statistically significant difference between Resazurin fluorescence and the number of epimastigotes and also with reading time after incubation ( $\mathrm{p}<0.05$, Table 6).

There was a positive, and linear correlation between the fluorescence and density of epimastigote at $1.6 \times 10^{6}$ cells $/ \mathrm{mL}$ for a $2.4 \mathrm{mM}$ Resazurin concentration at7hours of incubation ( $\mathrm{r}=0.8297)$, compared to the other two concentrations of Resazurin (Table 3). After incubation of $2.4 \mathrm{mM}$ Resazurin at $26^{\circ} \mathrm{C}$ for 7 hours, a very high and linear association $(\mathrm{r}=0.9876)$ in the range of $1.3 \times 10^{6}$ to $5.3 \times 10^{6}$ was observed in the fluorescence signal of the parasite (Table 3). For a comparative demonstration of the Resazurin based colorimetric assay, $1.8 \times 10^{6}$ epimastigotes/Ml (300 $\mu \mathrm{L} /$ well) with $2.4 \mathrm{mM}(25 \mu \mathrm{L})$ of Resazurin was seeded in a Corning ${ }^{\circledR}$ 24-well culture plate (Sigma Aldrich) containing to appreciate the color changes from blue to pink. The test showed a gradual colorimetric change in the three concentrations of Resazurin and one control (Figure 8).

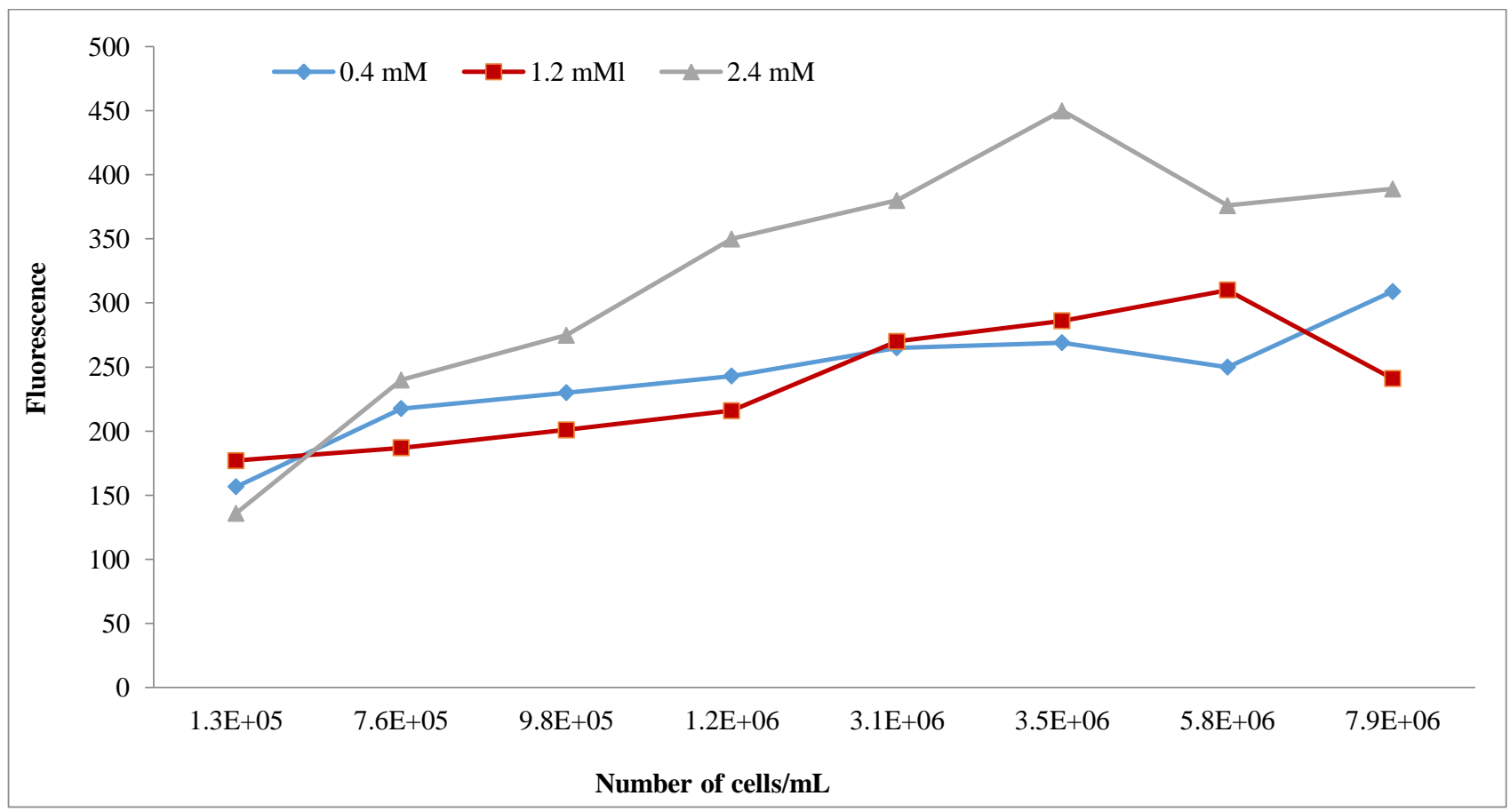

Figure 5. The relationship between the different fluorescence concentrations of Resazurin and the growth of epimastigote cultures after 7 hours of incubation time

Table 2. Statistical values of fluorescence for different cell concentrations concerning Resazurin concentrations

\begin{tabular}{|c|c|c|c|c|c|c|c|c|c|c|}
\hline \multirow[b]{2}{*}{ Resazurin } & \multicolumn{8}{|c|}{ Cells/ml and their respective fluorescence } & \multirow{2}{*}{$\begin{array}{c}\text { r- } \\
\text { value }\end{array}$} & \multirow{2}{*}{$\begin{array}{c}\text { P- } \\
\text { value }\end{array}$} \\
\hline & $1.3 \times 10^{5}$ & $7.6 \times 10^{5}$ & $9.8 \times 10^{5}$ & $1.2 \times 10^{6}$ & $3.1 \times 10^{6}$ & $3.5 \times 10^{6}$ & $5.8 \times 10^{6}$ & $7.9 \times 10^{6}$ & & \\
\hline $0.4 \mathrm{mM}$ & 156.63 & 217.6 & 230 & 243 & 280 & 292 & 268 & 290 & 0.752 & 0.0315 \\
\hline $1.2 \mathrm{mM}$ & 145 & 187 & 201 & 216 & 255 & 310 & 298 & 341 & 0.925 & 0.0010 \\
\hline $2.4 \mathrm{mM}$ & 184 & 240 & 275 & 341 & 380 & 489 & 450 & 490 & 0.865 & 0.0056 \\
\hline
\end{tabular}




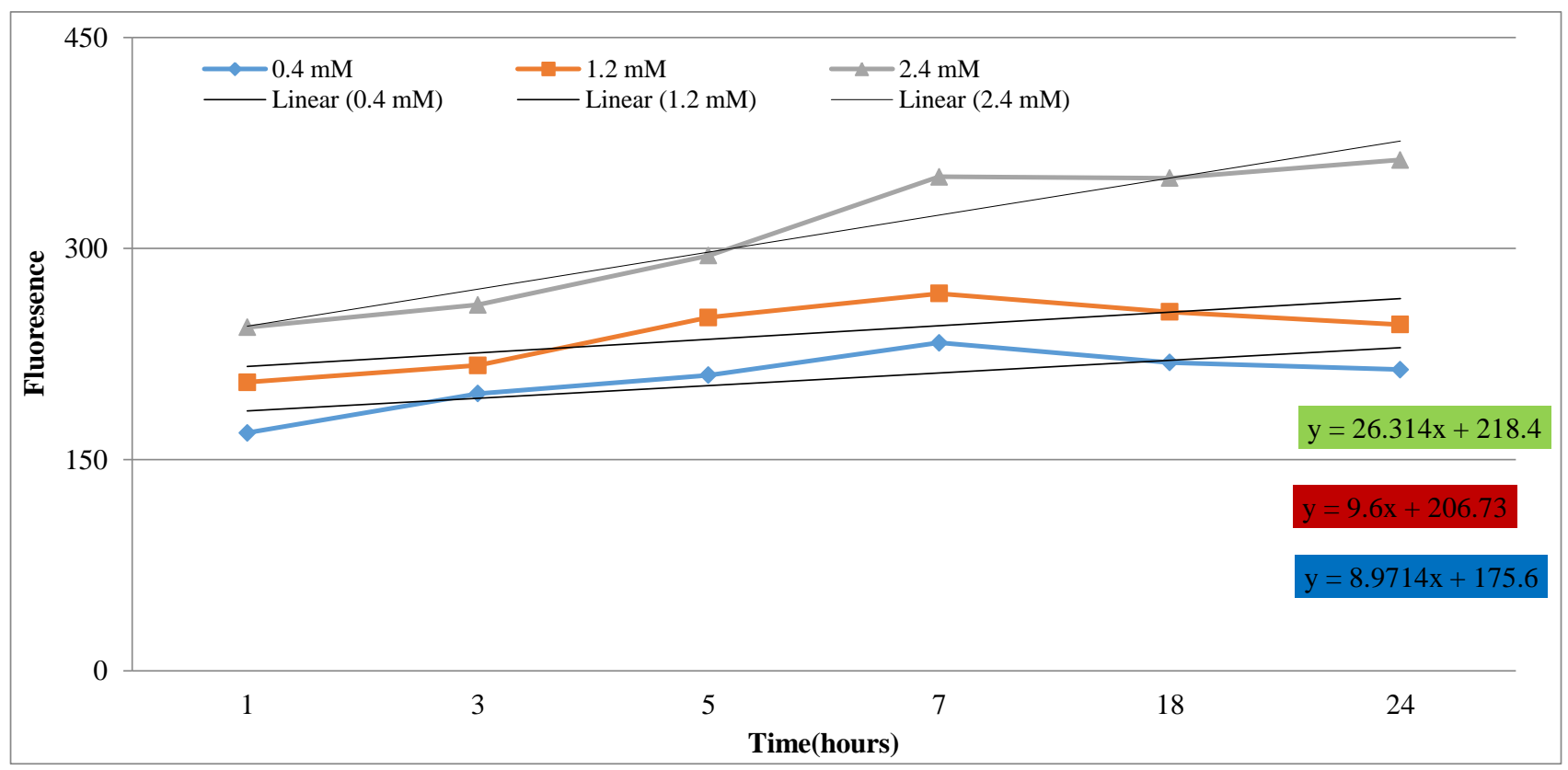

Figure 6. Fluorescence of Resazurin concerning incubation time and cell density of $1.6 \times 10^{6}$ epimastigotes $/ \mathrm{mL}$ of Trypanosoma theileri. All experiments were performed two times each in three duplicates, and average values were taken.

Table 3. Correlation between fluorescence signal and an incubation time of Trypanosoma theileri epimastigote

\begin{tabular}{|c|c|c|c|c|c|c|c|c|}
\hline \multirow[b]{2}{*}{ Resazurin } & \multicolumn{6}{|c|}{ Time (Hours) } & \multirow{2}{*}{ r -value } & \multirow{2}{*}{ P -value } \\
\hline & 1 & 3 & 5 & 7 & 18 & 24 & & \\
\hline $0.4 \mathrm{mM}$ & 169 & 197 & 210 & 233 & 219 & 214 & 0.5066 & 0.3051 \\
\hline $1.2 \mathrm{mM}$ & 205 & 217 & 251 & 268 & 257 & 246 & 0.4851 & 0.3295 \\
\hline $2.4 \mathrm{mM}$ & 244 & 260 & 295 & 351 & 350 & 363 & 0.8297 & 0.0410 \\
\hline
\end{tabular}

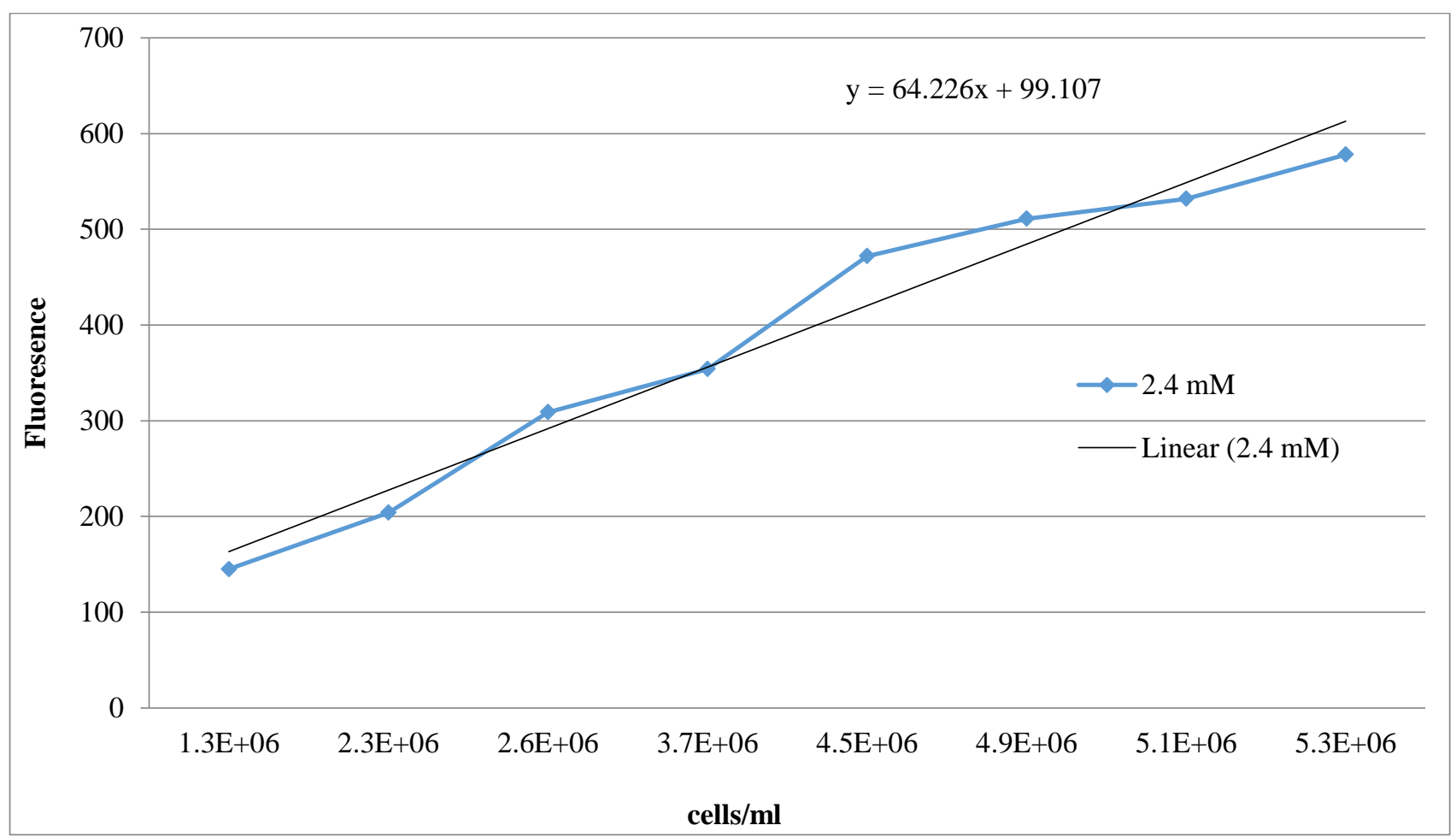

Figure 7. Standard curves for Resazurin fluorescence and the number of epimastigotes in the logarithmic growth phase, $\mathrm{r}$ $=0.9876, \mathrm{p}<0.05$ 


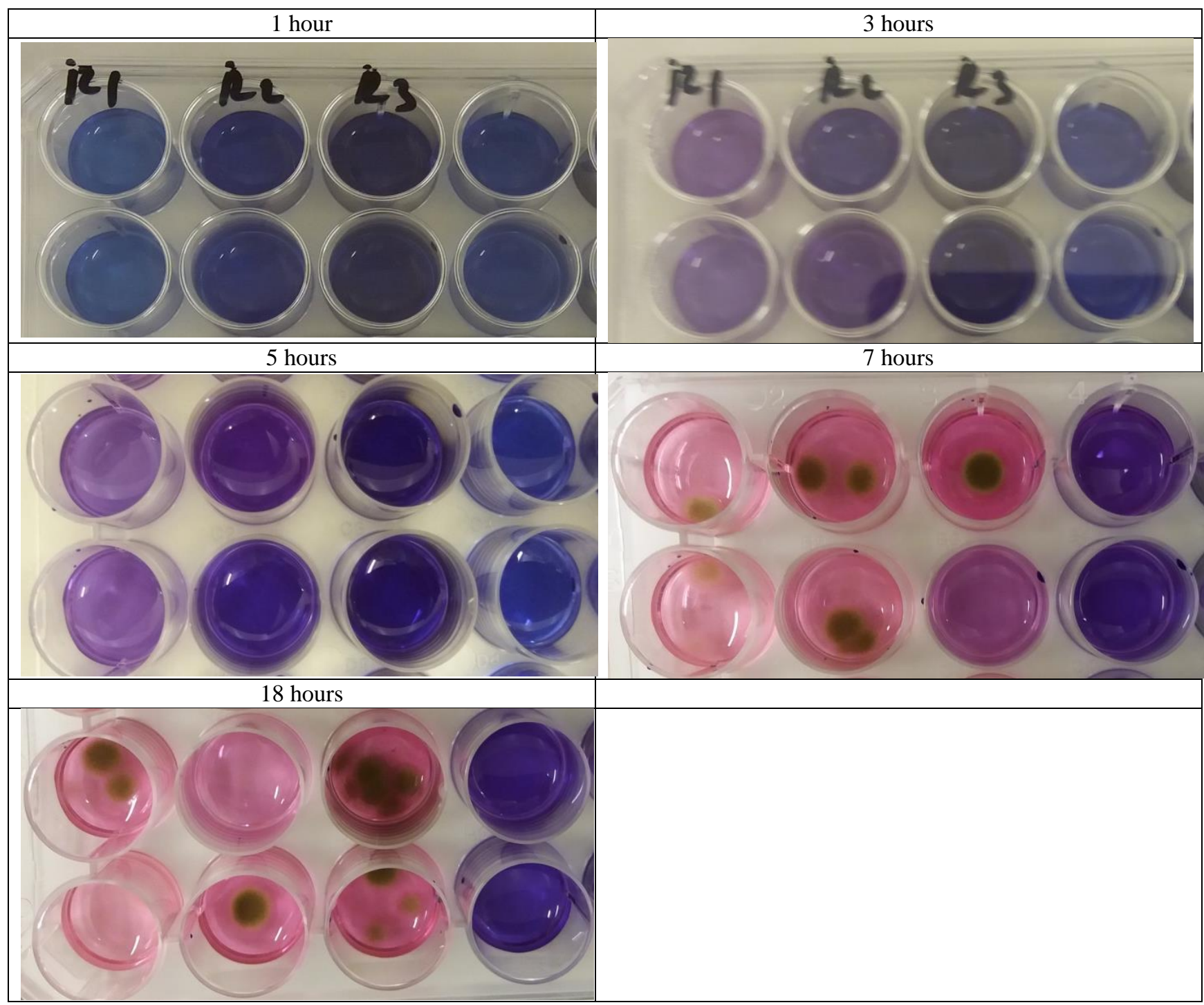

Figure 8. A plate to see the colorimetric changes of Resazurin $(2.4 \mathrm{mM})$ in each reading time after incubation with pentamidine $(80 \mathrm{ng} / \mathrm{mL})$

\section{Drug sensitivity assays}

Based on the optimized Resazurin assay for cell density, Resazurin concentration, and incubation period (Figure 5), Resazurin was deployed for the sensitivity of $T$. theileri epimastigote to pentamidine. Accordingly, Resazurin solution at a concentration of $2.4 \mathrm{mM}$ was used to assess the response of $T$. theileri epimastigotes to different concentrations (1-80 $\mathrm{ng} / \mathrm{mL}$ ) of pentamidine (Figure 9$)$. Therefore, there was a negative correlation $(-0.8826)$ between the reduction in fluorescence signal and a significant increase in drug concentration $(\mathrm{p}<0.05)$, as described in Figure 9and Table 4.

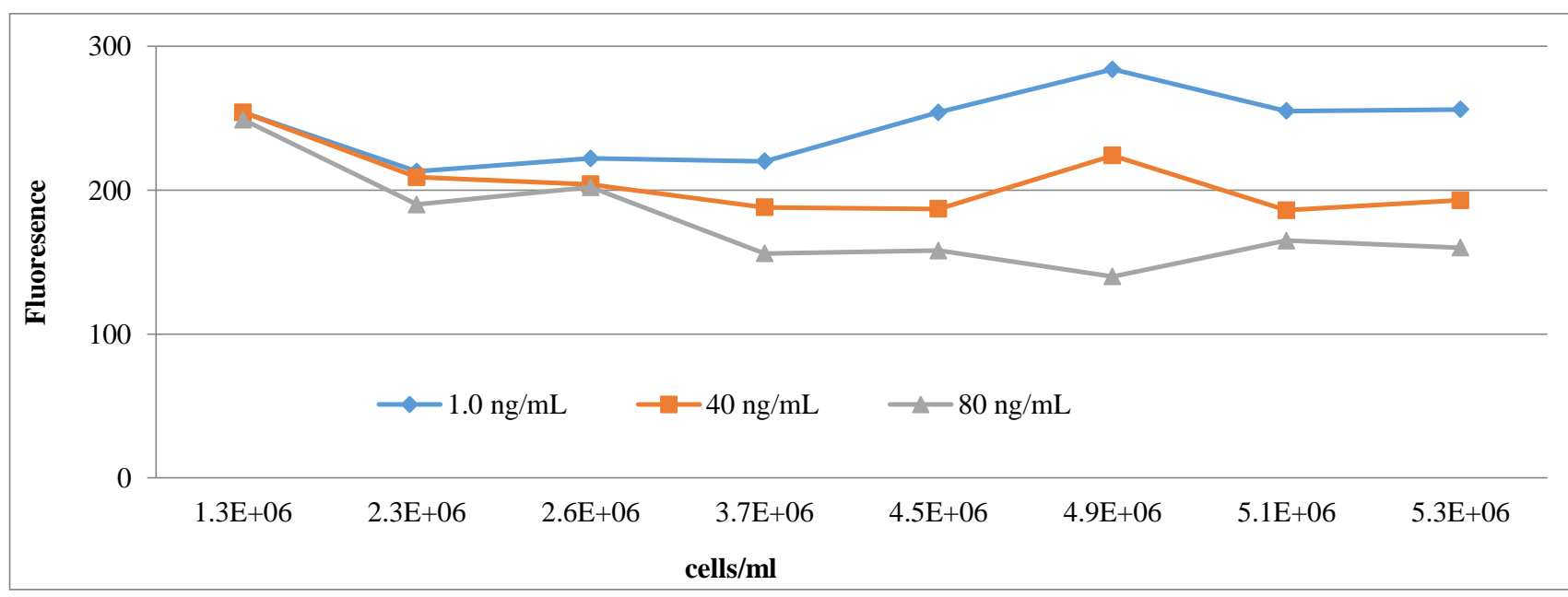

Figure 9. The reduction in fluorescence of epimastigotes of Trypanosoma theileri due to the pentamidine at different concentrations using $2.4 \mathrm{mM}$ Resazurin solution 
Table 4. Signals from Resazurin $(2.4 \mathrm{mM})$ after addition of three different concentrations of pentamidine

\begin{tabular}{lcccccccccc}
\hline & \multicolumn{9}{c}{ Cells/mL with its respective fluorescence } & \multicolumn{3}{c}{ r value } & P value \\
\hline Pentamidine & $1.3 \times 10^{6}$ & $2.3 \times 10^{6}$ & $2.6 \times 10^{6}$ & $3.7 \times 10^{6}$ & $4.5 \times 10^{6}$ & $4.9 \times 10^{6}$ & $5.1 \times 10^{6}$ & $5.3 \times 10^{6}$ & \\
\hline $1 \mathrm{ng} / \mathrm{ml}$ & 254 & 213 & 222 & 220 & 254 & 284 & 255 & 256 & 0.533 & 0.1740 \\
$40 \mathrm{ng} / \mathrm{ml}$ & 254 & 209 & 204 & 188 & 187 & 224 & 186 & 193 & -0.649 & 0.0817 \\
$80 \mathrm{ng} / \mathrm{ml}$ & 249 & 190 & 202 & 156 & 158 & 140 & 165 & 160 & -0.8826 & 0.0037 \\
\hline
\end{tabular}

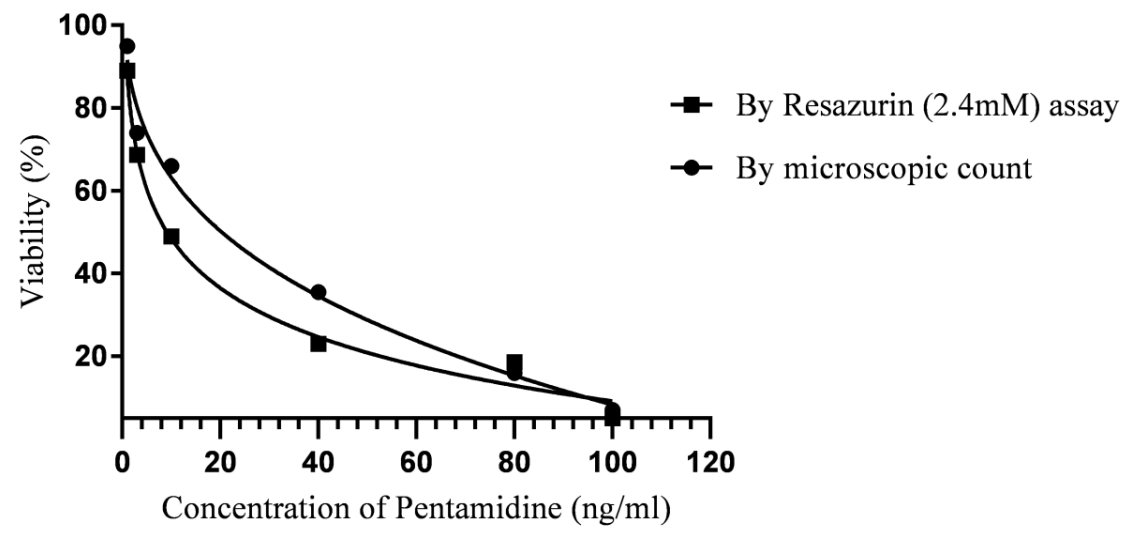

Figure 10. Viability of epimastigote after exposure to Pentamidine (1-100ng/mL) using Resazurin and microscopic counting

The role of Resazurin colorimetric assay was compared by calculating percentages of anti-epimastigotes (\% AE) activity of pentamidine( 1 to $100 \mathrm{ng} / \mathrm{mL}$ ). For this purpose, a microscopic count was done and calculated based on Equation 1as described in materials and methods. As indicated in Figure 10, the Resazurin assay and microscopic count were compared. As a result, there was a significant reduction in the percentage of viability of the epimastigotes as the pentamidine concentration increased after 48 hours of contact time. $\mathrm{IC}_{50}$ values of $9.25 \mathrm{ng} / \mathrm{mL}$ and $16.29 \mathrm{ng} / \mathrm{mL}$ were determined using Resazurin $(r=-0.957 ; \mathrm{p}<0.05)$ and manual counting $(\mathrm{r}=0.90, \mathrm{p}<0.05)$, respectively.

\section{Experimental infection of Trypanosoma theileri}

Before inoculating a calf with T. theileri, blood samples were taken to check whether there was a natural infection. No T. theileri was confirmed either in Giemsa stained slides or by culturing PBMC and buffy coat in RPMI 1640 and HMI 9 medium. The calf was inoculated intravenously through a jugular vein with a density of $4.5 \times 10^{6} / \mathrm{mL}$ to $7.3 \times$ $10^{6} / \mathrm{mL}$ in $5-8 \mathrm{ml}$. Moreover, the same amount and concentration were administered orally. Experimental infections were performed three times.

\section{PCR confirmation of Trypanosoma theileri}

WithDNeasy®Blood and Tissue Kit (Qiagen, Hilden, Germany) a very low concentration of DNA could be achieved. As a result, a higher DNA concentration $(16.5-274 \mu \mathrm{g} / \mathrm{m})$ could be extracted using the phenol-chloroform method. Gradient PCR amplification using T. theileri specific PCR (Tth625-PCR) revealed the 465 bp amplification product (Figure 11). In addition, the full-length $18 \mathrm{~S}$ ribosomal DNA sequence of $T$. theileri DNA was detected at $730 \mathrm{bp}$ (Figure 12). They were stained with ethidium bromide in 1\% agarose gel. A DNA ladder (100 bp) was used on the left side of the gel. The PCR amplification for the third primer (for annealing the Internal Transcribed Spacer (ITS) of the sequence of the ribosomal gene) was not included due to the poor image quality.

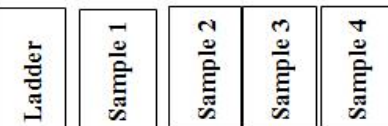

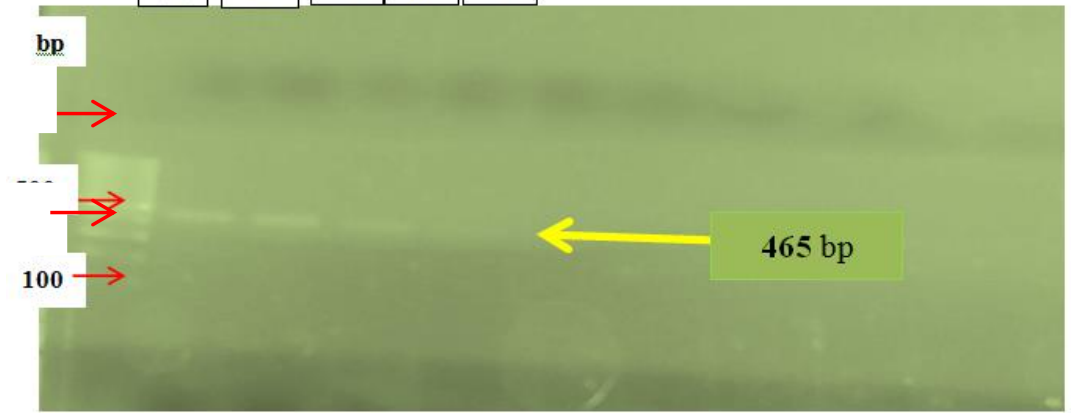

Figure 11. Detection of PCR of Trypanosoma theileri DNA from the cultured epimastigote using species-specific Tth625-PCR primers. The products were separated on a $1 \%$ agarose mini-gel 


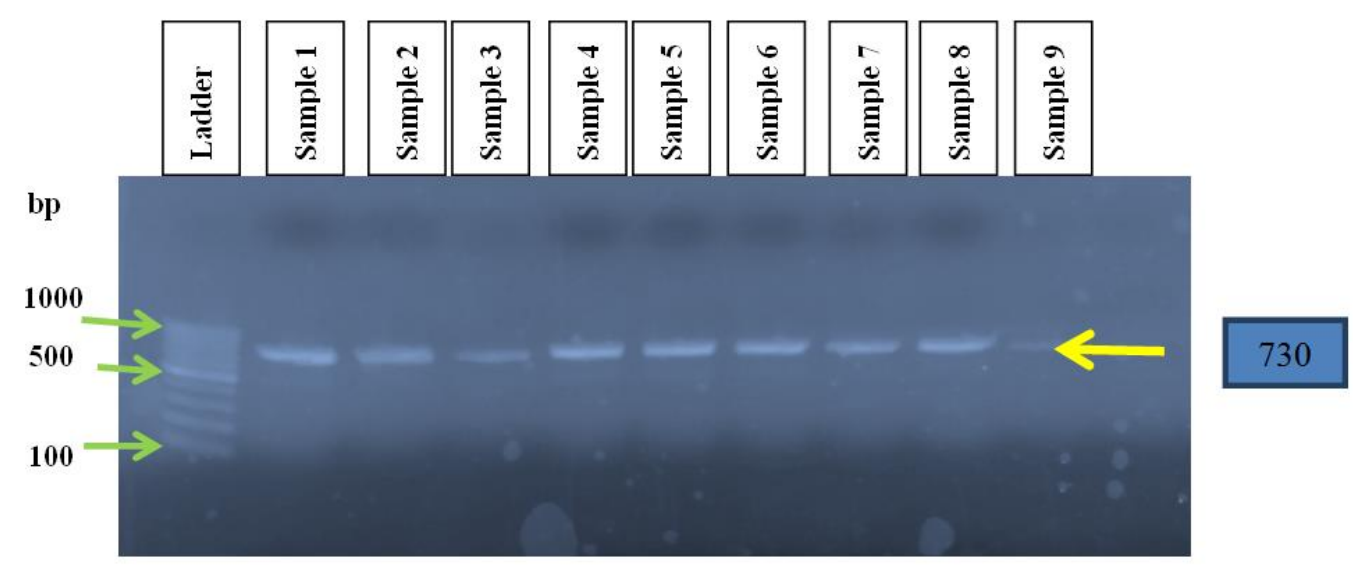

Figure 12. Detection of PCR of $T$. theileri of $18 \mathrm{~S}$ ribosomal DNA from the cultured epimastigote using $18 \mathrm{STnF} 2$ and 18STnR3. The products were separated on a $1 \%$ agarose mini-gel

\section{In silico analysis}

Multiple Sequence Alignment of the sequences of commonly used trypanocidal drug targets (Figure 13) with $T$. theileri nucleotide found in the NCBI database was run. Multiple Sequence Alignment was performed at both the genomic (DNA) and protein levels. The Basic Local Alignment Search Tool (BLAST) and Clustal W program (from ExPASy bioinformatics resource portal) was run to demonstrate homology between T. theileri genome/ proteome and /or drug target sequences. Based on the determined protein/nucleotide sequence, phylogenetic trees were constructed to find out the possibility of evolutionary relationships. At the genomic (DNA) level, no significant similarity was found. However, to a lesser extent, a similarity of 294/392 (75\%) was observed between T.grayi cathepsin L-like protein (CATL) gene (NCBI Gene bank accession No: XM_009318006.1) and HQ664735.1 of T. theileri isolate Tthb19 clone 3 cathepsin L-like protein (CATL) gene. The Cluster W alignment of these two similar genes from both species of Trypanosome was is described in Figure 14.

On the other hand, MSA among anti-trypanosome drug targets excluding T. theileri showed that there was above 99.85\% identity among accession number of XM_824336.1(100\%), J02771.1(99\%), and AF042286 (99\%). These listed accession numbers all indicated the Ornithine decarboxylase gene in T.brucei. In addition, the phylogenetic tree showed that these were similarities with accession Numbers: DQ887563.1 and XM_009318006.1, which both described the topoisomerase gene from T.congolense and the CATL gene from T. grayi, respectively (Figure 15).

\section{CLUSTAL format alignment by MAFFT FFT-NS-i (v7.215)}

XM_009318006.1 AACGGCGGCTTGATGGACGACGCCTTCACATGGATCATCCAGGACCACAACGGCACGGTG HQ $\overline{6} 64735.1$ AATGGCGGCTTGATGGACGACGCCTTCCAGTGGCTCGTGGATTCGAACAAGGGCAAGGTG

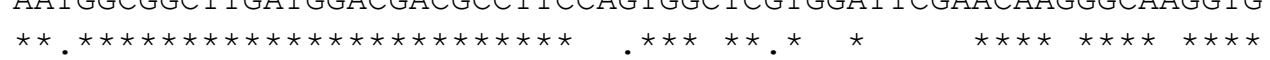

XM_009318006.1 GACACAGAGGCCAGCTACCCCTACGTCTCGGGCGCGGGCTACTCCCCGAAGTGCAGGACA HQ664735.1 TACACGGAGAACAGCTATCCCTACGTCTCTGGCTCCGGTCAAACGCCGGCGTGCTCGACA

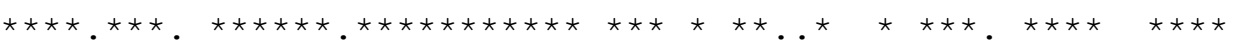

XM_009318006.1 GCTAGCCACGAGTTCGGCGCAGCCATCAGCGGCTACAATGACCTGCCGAATGATGAGGAC HQ664735.1 AGTGAACATGAGGTTGGTGCGACAATCACCGGCTTTGTGGACTTGCCAAAAGATGAGGAC

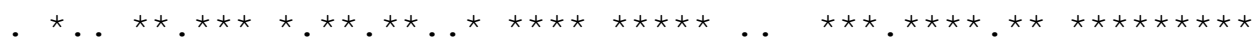

XM_009318006.1 AAGATGGCCGCGTGGCTGGCTGTCCACGGCCCCATTGCCATCGCCGTCGACGCCACCAGC HQ 664735.1 AAGATGGCGGCATGGCTTGCTACCAATGGCCCCATTGCTATCGCTGTCGACGCCAACAGC

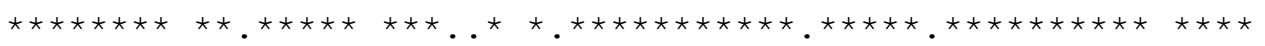

XM_009318006.1 TTCCAGTTCTACATGGGTGGCGTCCTGACGAACTGCATCTCTGAGCAGCTCGACCACGGG HQ 664735.1 TTTCTGTCGTACGTAAGTGGTGTTTTGACGAACTGTGAATCGGACCAGTTGAACCACGGT

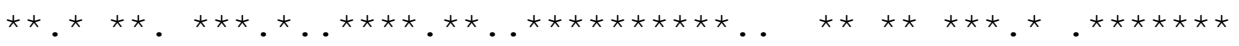

XM_009318006.1 GTGCTTCTTGTGGGCTACGACGACAGCAACAGCCCGCCGTACTGGATCATCAAGAACTCG HQ $\overline{6} 64735.1$ GTGCTTCTTGTCGGCTACGACGACAGCAGCAATCCACCGTACTGGATCATCAAGAAC---

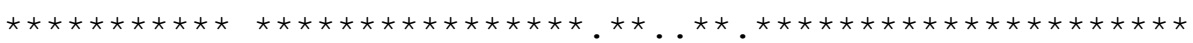

Figure 13. Cluster W alignment of Trypanosoma theileri (HQ664735.1) and T.grayi (XM_009318006.1) for the cathepsin L-like protein gene 


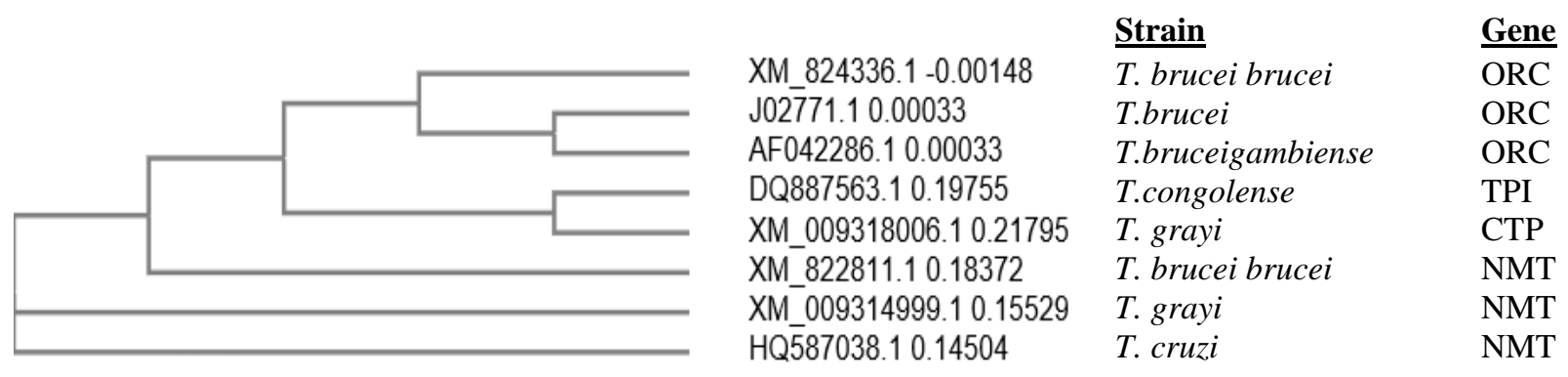

Figure 14. Multiple sequence alignments phylogenetic tree of the genome (DNA) of trypanosome showing relationships between common drug targets. ORC: Ornithine decarboxylase, TPI: Topoisomerase, CTP: Cathepsin L-like protein partial mRNA, NMT: N-myristoyl transferase

Table 5. Percentage of identity and divergence between common anti-trypanosomal drug targets identity

\begin{tabular}{|c|c|c|c|c|c|c|c|c|c|c|}
\hline \multirow{9}{*}{$\begin{array}{l}\ddot{U} \\
\vec{D} \\
.00 \\
\vec{\Delta} \\
\vec{\Delta}\end{array}$} & & 1 & 2 & 3 & 4 & 5 & 6 & 7 & 8 & \\
\hline & 1: XM_824336.1 & 100 & 99.93 & 99.85 & 44.01 & 41.48 & 40.87 & 44.4 & 42.34 & 1 \\
\hline & 2: J02771.1 & 99.93 & 100 & 99.93 & 42.89 & 41.22 & 41.2 & 43.46 & 42.2 & 2 \\
\hline & 3: AF042286.1 & 99.85 & 99.93 & 100 & 43.07 & 41.22 & 41.25 & 43.42 & 42.08 & 3 \\
\hline & 4: DQ887563.1 & 44.01 & 42.89 & 43.07 & 100 & 58.45 & 43.5 & 44.17 & 43.38 & 4 \\
\hline & 5: XM_009318006.1 & 41.48 & 41.22 & 41.22 & 58.45 & 100 & 41.52 & 43.44 & 40 & 5 \\
\hline & 6:XM_822811.1 & 40.87 & 41.2 & 41.25 & 43.5 & 41.52 & 100 & 63.21 & 65.15 & 6 \\
\hline & 7: XM_009314999.1 & 44.4 & 43.46 & 43.42 & 44.17 & 43.44 & 63.21 & 100 & 68.7 & 7 \\
\hline & 8: HQ587038.1 & 42.34 & 42.2 & 42.08 & 43.38 & 40 & 65.15 & 68.7 & 100 & 8 \\
\hline
\end{tabular}

XM 824336.1 J0 $\overline{2} 771.1$ AF042286.1

XM 824336.1 J0 $\overline{2} 771.1$ AF0 42286.1

XM 824336.1 J0 2771.1 $\mathrm{AF} 042286.1$

XM 824336.1 J0 2771.1 AF 042286.1

XM 824336.1 J0 2771.1 $\mathrm{AF} 042286.1$

XM_824336.1 J0 $\overline{2} 771.1$ AF0 42286.1

XM 824336.1 J0 $\overline{2} 771.1$ AF0 42286.1

XM_824336.1 J0 $\overline{2} 771.1$ AF0 42286.1

XM 824336.1 J0 $\overline{2} 771.1$ AF0 42286.1
TCTGTGAATTGTCTTGTAGCACAAACGGAGAAATCTATGGACATTGTCGTGAACGATGAC TCTGTGAATTGTCTTGTAGCACAAACGGAGAAATCTATGGACATTGTCGTGAACGATGAC TCTGTGAATTGTCTTGTAGCACAAACGGAGAAATCTATGGACATTGTCGTGAACGATGAC

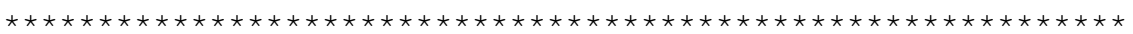

TTGAGTTGTCGCTTTCTTGAAGGGTTTAATACGAGGGATGCCCTCTGTAAAAAGATCAGT TTGAGTTGTCGCTTTCTTGAAGGGTTTAATACGAGGGATGCCCTCTGTAAAAAGATCAGT TTGAGTTGTCGCTTTCTTGAAGGGTTTAATACGAGGGATGCCCTCTGTAAAAAGATCAGT

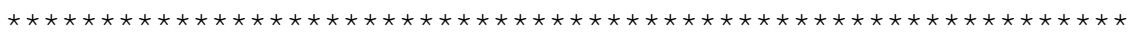

ATGAATACGTGTGACGAAGGTGATCCGTTTTTTGTTGCCGATCTCGGGGACATTGTAAGG ATGAATACGTGTGACGAAGGTGATCCGTTTTTTGTTGCCGATCTCGGGGACATTGTAAGG ATGAATACGTGTGACGAAGGTGATCCGTTTTTTGTTGCCGATCTCGGGGACATTGTAAGG

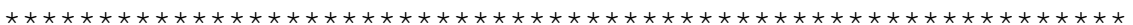

AAGCACGAAACATGGAAAAAATGCCTTCCCCGCGTCACGCCGTTTTACGCGGTCAAATGC AAGCACGAAACATGGAAAAAATGCCTTCCCCGCGTCACGCCGTTTTACGCGGTCAAATGC AAGCACGAAACATGGAAAAAATGCCTTCCCCGCGTCACGCCGTTTTACGCGGTCAAATGC

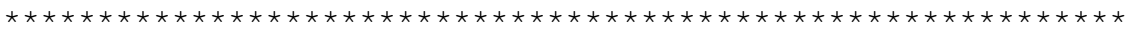

AACGATGACTGGCGCGTACTTGGAACGCTGGCGGCTCTCGGCACGGGATTTGATTGTGCT AACGATGACTGGCGCGTACTTGGAACGCTGGCGGCTCTCGGCACGGGATTTGATTGTGCT AACGATGACTGGCGCGTACTTGGAACGCTGGCGGCTCTCGGCACGGGATTTGATTGTGCT

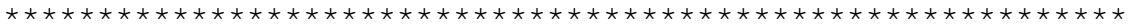

AGCAACACTGAGATACAACGTGTGAGAGGCATTGGTGTGCCACCGGAAAAAATAATATAT AGCAACACTGAGATACAACGTGTGAGAGGCATTGGTGTGCCACCGGAAAAAATAATATAT AGCAACACTGAGATACAACGTGTGAGAGGCATTGGTGTGCCACCGGAAAAAATAATATAT

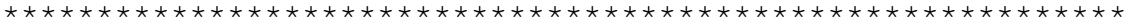

GCGAACCCTTGTAAACAAAATTCACACATACGGTACGCGCGTGATAGCGGCGTTGATGTC GCGAACCCTTGTAAACAAATTTCACACATACGGTACGCGCGTGATAGCGGCGTTGATGTC GCGAACCCTTGTAAACAAATTTCACACATACGGTACGCGCGTGATAGCGGCGTTGATGTC

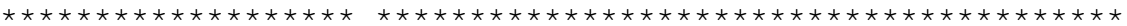

ATGACATTTGATTGCGTGGATGAACTGGAAAAGGTCGCTAAAACGCATCCAAAGGCAAAG ATGACATTTGATTGCGTGGATGAACTGGAAAAGGTCGCTAAAACGCATCCAAAGGCAAAG ATGACATTTGATTGCGTGGATGAACTGGAAAAGGTCGCTAAAACGCATCCAAAGGCAAAG

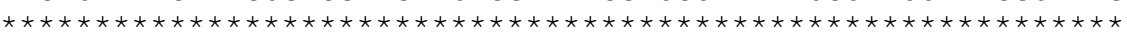
ATGGTATTAAGAATTTCTACGGATGATTCGTTGGCTCGATGCCGTCTCAGTGTGAAGTTT ATGGTATTAAGAATTTCTACGGATGATTCGTTGGCTCGATGCCGTCTCAGTGTGAAGTTT ATGGTATTAAGAATTTCTACGGATGATTCGTTGGCTCGATGCCGTCTCAGTGTAAAGTTT

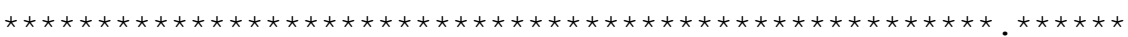


XM_824336.1 J0 $\overline{2} 771.1$ AF0 42286.1

XM 824336.1 J0 $\overline{2} 771.1$ AF0 42286.1

XM_824336.1 J0 $\overline{2} 771.1$ AF0 42286.1

XM 824336.1 J0 $\overline{2} 771.1$ AF0 42286.1

XM 824336.1 J0 $\overline{2} 771.1$ AF0 42286. 1

XM 824336.1 J0 $\overline{2} 771.1$ AF0 42286.1

XM 824336.1 J02771. 1 AF0 42286.1

XM 824336.1 J0 $\overline{2} 771.1$ AF0 02286.1

XM 824336.1 J0 2771.1 AF0 42286.1

XM_824336.1 J0 $\overline{2} 771.1$ AF0 42286.1

XM 824336.1 J0 $\overline{2} 771.1$ AF0 42286.1

XM_824336.1 J0 $\overline{2} 771.1$ AF0 42286.1

XM 824336.1 J0 $\overline{2} 771.1$ AF0 42286. 1
GGTGCAAAGGTGGAAGACTGTAGGTTTATCTTGGAGCAGGCAAAGAAACTGAATATCGAC GGTGCAAAGGTGGAAGACTGTAGGTTTATCTTGGAGCAGGCAAAGAAACTGAATATCGAC GGTGCAAAGGTGGAAGACTGTAGGTTTATCTTGGAGCAGGCAAAGAAACTGAATATCGAC

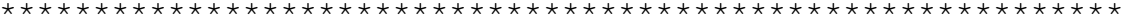

GTCACTGGTGTGAGTTTTCACGTGGGAAGCGGATCTACAGATGCCTCTACCTTCGCTCAA GTCACTGGTGTGAGTTTTCACGTGGGAAGCGGATCTACAGATGCCTCTACCTTCGCTCAA GTCACTGGTGTGAGTTTTCACGTGGGAAGCGGATCTACAGATGCCTCTACCTTCGCTCAA

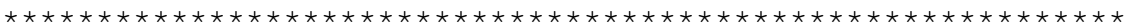

GCCATATCTGACTCCCGTTTCGTTTTCGACATGGGTACTGAGCTTGGGTTCAATATGCAC GCCATATCTGACTCCCGTTTCGTTTTCGACATGGGTACTGAGCTTGGGTTCAATATGCAC GCCATATCTGACTCCCGTTTCGTTTTCGACATGGGTACTGAGCTTGGGTTCAATATGCAC $\star * * * * * * * * * * * * * * * * * * * * * * * * * * * * * * * * * * * * * * * * * * * * * * * * * * * * * * * * * * *$

ATTCTTGATATCGGTGGTGGGTTTCCAGGGACGAGGGATGCACCACTTAAATTTGAAGAG ATTCTTGATATCGGTGGTGGGTTTCCAGGGACGAGGGATGCACCACTTAAATTTGAAGAG ATTCTTGATATCGGTGGTGGGTTTCCAGGGACGAGGGATGCACCACTTAAATTTGAAGAG

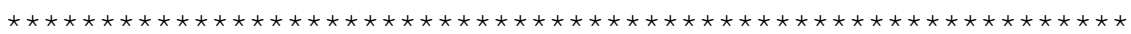
ATTGCTGGTGTCATCAACAATGCGCTGGAAAAACATTTTCCACCTGACCTCAAGCTTACC ATTGCTGGTGTCATCAACAATGCGCTGGAAAAACATTTTCCACCTGACCTCAAGCTTACC ATTGCTGGTGTCATCAACAATGCGCTGGAAAAACATTTTCCACCTGACCTCAAGCTTACC

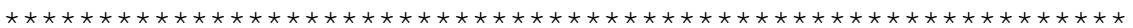
ATTGTTGCCGAGCCGGGAAGGTACTACGTTGCTTCAGCTTTCACACTTGCCGTAAATGTT ATTGTTGCCGAGCCGGGAAGGTACTACGTTGCTTCAGCTTTCACACTTGCCGTAAATGTT ATTGTTGCCGAGCCGGGAAGGTACTACGTTGCTTCAGCTTTCACACTTGCCGTAAATGTT

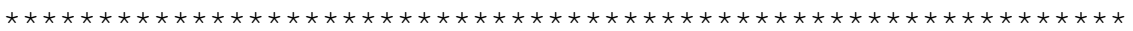

ATTGCCAAGAAGGTGACACCAGGGGTTCAGACCGACGTCGGTGCCCATGCTGAATCAAAC ATTGCCAAGAAGGTGACACCAGGGGTTCAGACCGACGTCGGTGCCCATGCTGAATCAAAC ATTGCCAAGAAGGTGACACCAGGGGTTCAGACCGACGTCGGTGCCCATGCTGAATCAAAC

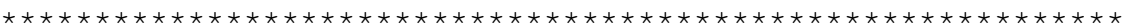

GCACAGAGTTTTATGTATTATGTGAATGATGGCGTGTATGGTTCATTTAATTGCATCCTG GCACAGAGTTTTATGTATTATGTGAATGATGGCGTGTATGGTTCATTTAATTGCATCCTG GCACAGAGTTTTATGTATTATGTGAATGATGGCGTGTATGGTTCATTTAATTGCATCCTG

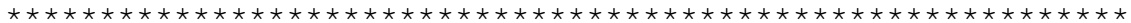

TATGACCACGCAGTCGTCAGGCCTTTGCCCCAGAGGGAGCCAATCCCCAATGAAAAGCTC TATGACCACGCAGTCGTCAGGCCTTTGCCCCAGAGGGAGCCAATCCCCAATGAAAAGCTC TATGACCACGCAGTCGTCAGGCCTTTGCCCCAGAGGGAGCCAATCCCCAATGAAAAGCTC

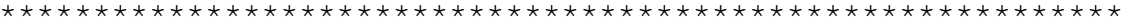

TATCCCTCAAGTGTATGGGGTCCCACATGTGATGGTCTTGATCAGATAGTTGAACGATAC TATCCCTCAAGTGTATGGGGTCCCACATGTGATGGTCTTGATCAGATAGTTGAACGATAC TATCCCTCAAGTGTATGGGGTCCCACATGTGATGGTCTTGATCAGATAGTTGAACGATAC

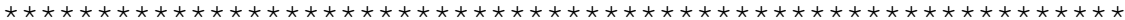

TATCTTCCCGAGATGCAAGTGGGGGAATGGCTGCTCTTTGAGGATATGGGTGCCTACACG TATCTTCCCGAGATGCAAGTGGGGGAATGGCTGCTCTTTGAGGATATGGGTGCCTACACG TATCTTCCCGAGATGCAAGTGGGGGAATGGCTGCTCTTTGAGGATATGGGTGCCTACACG

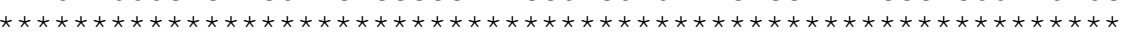

GTCGTAGGAACTTCTTCCTTTAATGGATTCCAGAGTCCGACTATTTACTATGTAGTCTCC GTCGTAGGAACTTCTTCCTTTAATGGATTCCAGAGTCCGACTATTTACTATGTAGTCTCC GTCGTAGGAACTTCTTCCTTTAATGGATTCCAGAGTCCGACTATTTACTATGTAGTCTCC

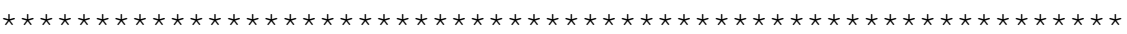
GGGCTACCAGACCATGTTGTCCGGGAGTTGAAAAGTCAAAAATCATAA--.--.--.-GGGCTACCA GACCATGTTGTCCGGGA GTTGAAAA GTCAAAAATCATAAATGGAAGCGAAG GGGCTACCAGACCATGTTGTCCGGGAGTTGAAAAGTCAAAAATCATAAATGGAAGCGAAG

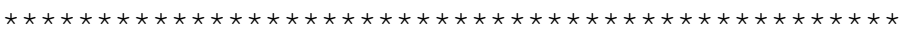

Figure 15. Cluster W alignment between the three homologous sequences of anti-trypanosome drug targets

Furthermore, apart from the genomic level (DNA), MSA was conducted at the protein level. After the BLAST and Cluster $\mathrm{W}$ analysis of protein sequences of drug targets with T. theileri proteome, which was found in NCBI databases, these drug targets showed a 12/17 (71\%) homology with hypothetical T. theileri proteins (TM35) and pyruvate kinase (Figures 17 and 18).

On the other hand, among the drug targets themselves, the highest identity was detected in accession number ofXP_829429.1 (445/445(100\%)), which indicates ornithine decarboxylase protein (Figure 19). Furthermore, there was homology with AAD02222.1 and AAA30219.1, which encode the same protein from T.grayi and T.brucei, respectively. The MSA and the phylogenetic trees witnessed the homology of these sequences. 


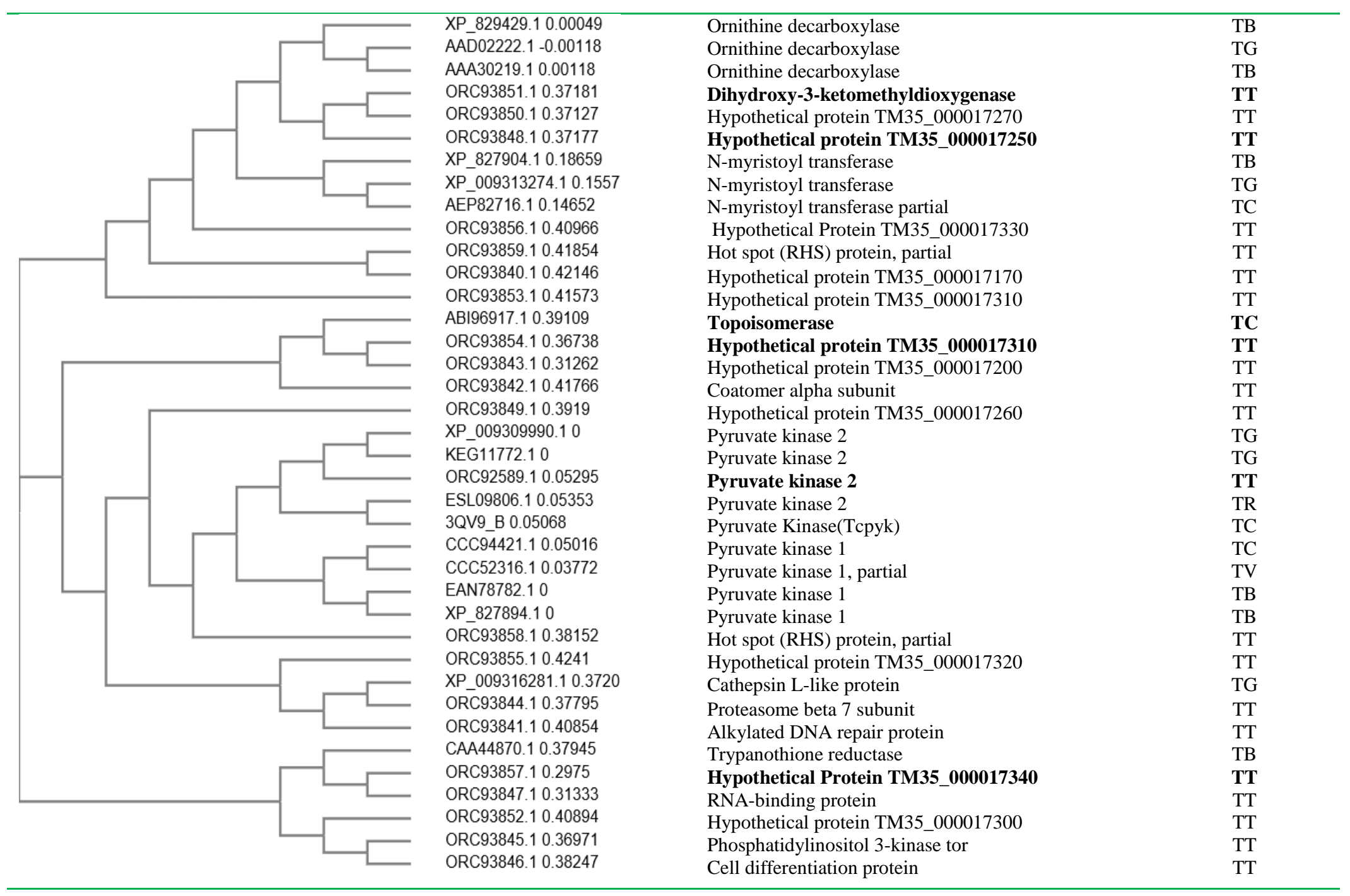

Figure 16. Phylogenetic tree following MSA of the drug targets and Trypanosoma theileri. TB: T. brucei, TG: T. grayi, TT: T. theileri, TC: T. cruzi, TR: T. rangeli, TV: T. vivax, TC: T.congolense 
XP 009309990.1 GPSTQSVEALKGLMKSGMSVARMNFSHGSHE-YHQATINNVRTAAAELGLHIGIALDTK 3720

KEG117721

3720

ORC 925891

3720

CCC 944211

3720

CCC523161

3720

ESL098061

3720

3QV9 B

3720

GPSTQSVEALKGLMKSGMSVARMNFSHGSHE-YHQATINNVRTAAAELGLHIGIALDTK

GPSTQSVEALKGLMKSGMSVARMNFSHGSHE-YHQTTINNVRTAAAELGMHIGIALDTK

GPSTQSVEALKGLMKSGMSVARMNFSHGSYE-YHQTTINNVRAAAAELGLHIGIALDTK

GPSTQSVEALKGLMKSGMSVARMNFSHGSHE-YHQTTIKNVRQAAAELGLHIGIALDTK

GPSTQSIEALRSLIKSGMSVARMNFSHGSHE-YHQTTINNVRAASAELGVHIGIALDTK

GPSTQSVEALKGLIRSGMSVARMNFS HGSHE-YHQTTINNLRAAATELGAHIGLALDTK

XP_0093099901

3780

GPEIRTGLFVGGEAVL-NPGDTVFVTTDPAFE-----------KKGTKEKFYVDYPRLAT

KEG117721

3780

ORC925891

3780

GPEIRTGLFVGGEAVL-NPGDTVFVTTDPAFE----------KKGTKEKFYVDYPRLAT

GPEIRTGLFVGGEAIL-MTGDTVLVTTDPAFE----------KTGTKEKFYIDYPRLAT

XP_0093099901

3850

KEG117721

3850

ORC925891

3850

CCC 944211

3850

CCC523161

3850

ESL098061

3850

3QV9_B

3850

EAN787821

3850

$X P \_8278941$

$38 \overline{5} 0$

----FHRLTDRKGCNLPGCDVDLPAVSAKDREDLKFGVEQGVDI IFASFIRTAEQVQEVR

----FHRLTDRKGCNLPGCDVDLPAVSAKDREDLKFGVEQGVDI I FASFIRTAEQVQEVR

----GHRLTDRKGCNLPGCEVDLPAVSAKDREDLKFGVEQGVDMIFASFIRTAEQVREVR

----HHRLTDRKGINLPGCEVDLPAVSEKDRKDLQFGVEQGVDMIFASFIRTADQVREVR

----HHRLTDRKGCNLPGCDVELPAVSEKDRKDLIFGVEQGVDMIFASFIRTAEQVREVR

----AHYLTDRKGCNLPGCEVDLPAVSEKDREDLKFGVEQGVDMIFASFIRTAEQVREVR

----AHFLTDRKGCNLPGCEVDLPAVSEKDREDLKFGVEQGI DMVFASFIRTAEQVQEVR

----HHRLTDRRGINLPGCEVDLPAVSEKDRKDLEFGVAQGVDMIFASFIRTAEQVREVR

----HHRLTDRRGINLPGCEVDLPAVSEKDRKDLEFGVAQGVDMIFASFIRTAEQVREVR

KEG117721

3970

ORC 925891

3970

$\operatorname{CCC} 944211$

3970

CCC523161

3970

ESL098061

3970

3QV9_B

3970

EAN787821

3970

$\mathrm{XP} \_8278941$

$39 \overline{7} 0$

AQMMLISKCNVAGK-----------------PVICATQMLESMTANPRP---TRAEVSD

AQMTLISKCNVAGK---------------PVICATQMLESMTTNPRP---TRAEVSD

AQMCIISKCNVAGK----------------PVICATQMLESMTTNPRP---TRAEVTD

AQMCI ISKCNVAGK-----------------PVICATQMLESMTTNPRP---TRAEVSD

AQMILISKCNVAGK-----------------PVICATQMLESMTTNPRP---TRAEVSD

AQMILISKCNVAGK----------------PVICATQMLESMTTNPRP---TRAEVSD

AQMCI ISKCNVVGK-----------------PVICATQMLESMTSNPRP---TRAEVSD

AQMCI ISKCNVVGK-----------------PVICATQMLESMT SNPRP---TRAEVSD 


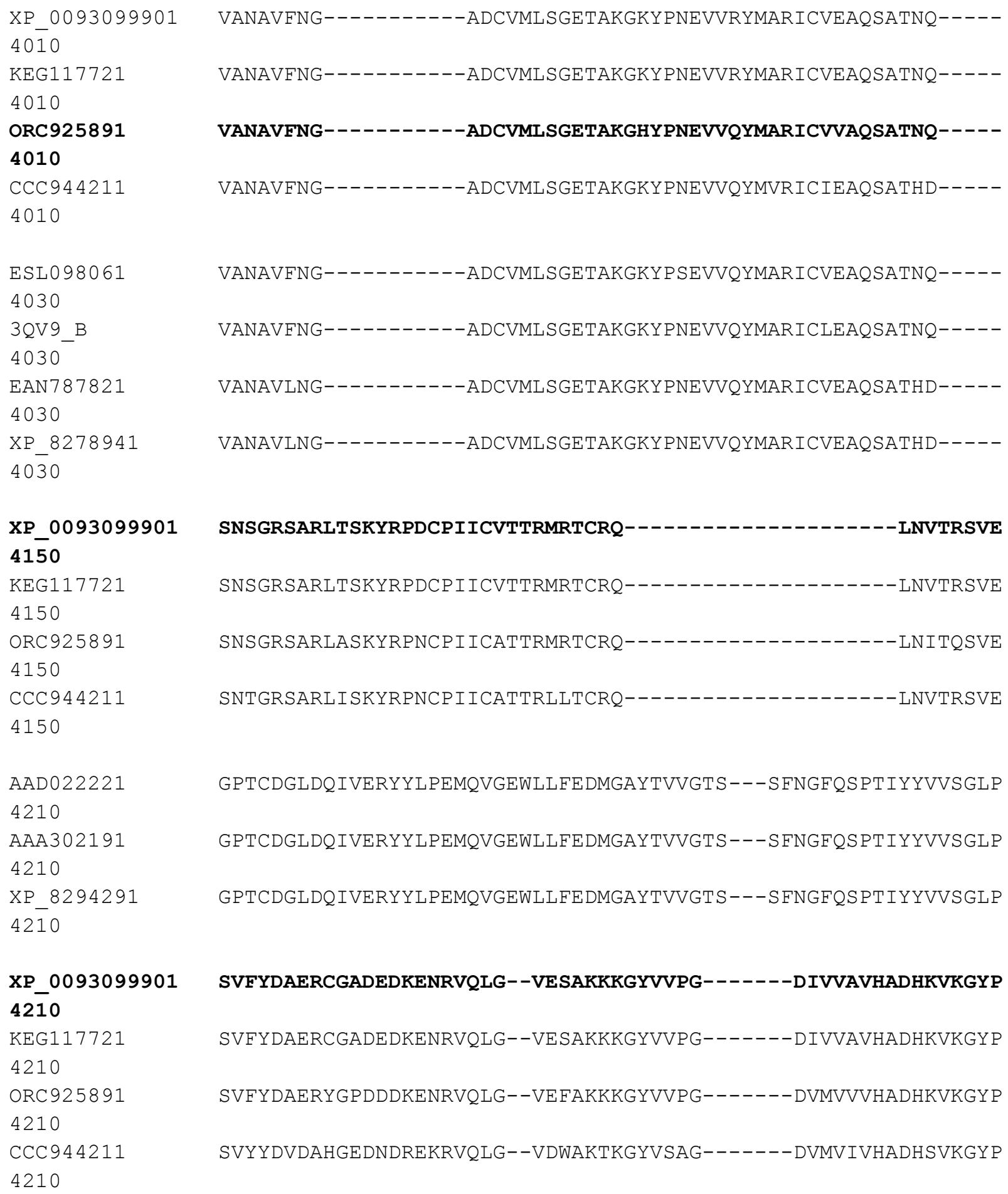

Figure 17. Alignment of drug targets with Trypanosoma theileri (XP_0093099901) protein found in the NCBI database 
AAD022221

AAA302191

XP_8294291

ESL̄098061

3QV9 B

XP $0 \overline{0} 93099901$

$\mathrm{KE} \overline{\mathrm{G}} 117721$

CCC523161

EAN787821

XP 8278941

AAD022221

AAA302191

XP 8294291

EST̄098061

3QV9 B

XP_Ō̄o3099901

$\mathrm{KE} \overline{\mathrm{G}} 117721$

CCC523161

EAN787821

XP 8278941

CC̄̄ 944211

XP 0093132741

$\mathrm{AE} \overline{\mathrm{P}} 827161$

AAD 022221

AAA302191

XP 8294291

ESL̄098061

3QV9_B

XP $0 \overline{0} 93099901$

$\mathrm{KE} \overline{\mathrm{G}} 117721$

CCC523161

EAN787821

XP 8278941

CCC̄ 944211

$\mathrm{XP} 0093132741$

$\mathrm{AE} \overline{\mathrm{P}} 827161$

XP 8279041

AAD022221
XAA302191
XP 8294291
EST 098061
XP 0093099901
KEG 117721

EAN787821

XP_8278941

AAD 022221

AAA302191

XP 8294291

EST̄098061

3QV9 B

XP $0 \overline{0} 93099901$

$\mathrm{KE} \overline{\mathrm{G}} 117721$

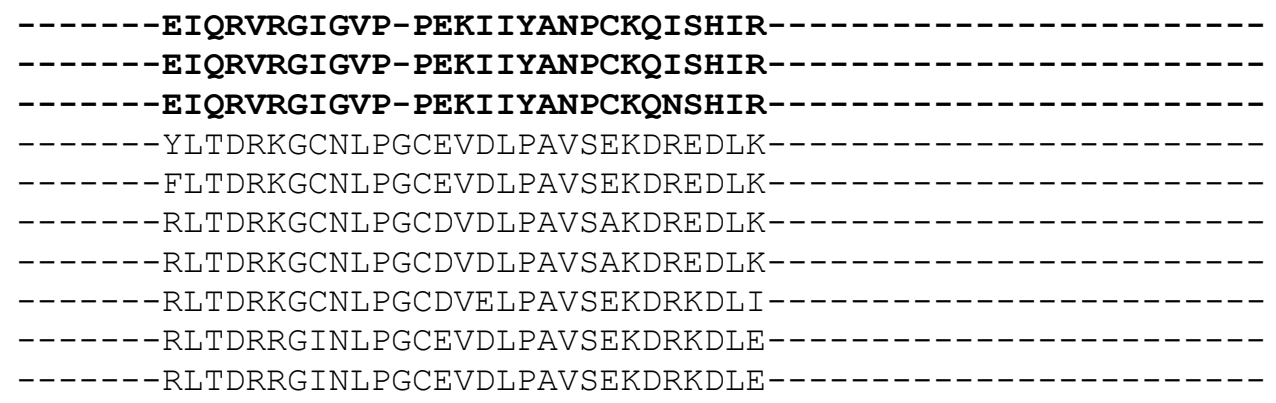

--YARDSGVDVMTFDCVDELEKVAKTHPKAKMVLR-ISTDDSLARCRLSVKFGAKVEDCR 610 --YARDSGVDVMTFDCVDELEKVAKTHPKAKMVLR-ISTDDSLARCRLSVKFGAKVEDCR --YARDSGVDVMTFDCVDELEKVAKTHPKAKMVLR-ISTDDSLARCRLSVKFGAKVEDCR --FGVEQGVDMIFASF IRTAEQVREVRAALGEKGKDI LVISKIENHQGVQNIDAI IEASD --FGVEQG I DMVFASFIRTAEQVQEVREALGEKGKDILI ISKIENHQGVQNIDGIIEASD --FGVEQGVDI IFASFIRTAEQVQEVRAALGEKGKDTLVISKIENHQGVQNIDGI IAVSD --FGVEQGVDI IFASFIRTAEQVQEVRAALGEKGKDTLVISKIENHQGVQNIDGI IAVSD --FGVEQGVDMIFASF IRTAEQVREVRAVLGEKGKDTMI ISK IENHQGVQNIDAIIEASD --FGVAQGVDMIFASF IRTAEQVREVRAALGEKGKDI LI ISKIENHQGVQNI DS I IEASN --FGVAQGVDMIFASFIRTAEQVREVRAALGEKGKDILI ISKIENHQGVQNIDSI IEASN --FGVEQGVDMIFASF IRTADQVREVRAALGEKGKDTLI I SKIENHQGVQNI DAI IEASD --ENHLEPR I ICE INF LCVHKQLREKRMAPI L IQEVTRRVNLLN IWQA IYTAGALLPTP--EXYLEPRKICE INFLCVHKLLRAKRLAPI LIKEVTRRVHLMNIWQAVYTAGRLLPTP-

F- ILAKKLNIDVTGVSFHVGSGSTDASTFAQ-----1----AISDSRFVFDMG F--ILEQAKKLNIDVTGVSFHVGSGSTDASTFAQ------.----AISDSRFVFDMG G--IMVARGDLGVEIAAEKVVVAQMILISKCNVAG-----------KPVICATQMLESMT G--IMVARGDLGVEIPAEKVVVAQMILISKCNVAG-----------KPVICATQMLESMT G--IMVARGDLGVEI PAEKVVVAQMMLISKCNVAG----------KPVICATQMLESMT G--IMVARGDLGVEI PAEKVVVAQMMLISKCNVAG-----------KPVICATQMLESMT G--IMVARGDLGVEI PAEKVVVAQMC I I SKCNVAG----------KPVICATQMLESMT G--IMVARGDLGVEI PAEKVCVAQMCI I SKCNVVG-----------KPVICATQMLESMT G--IMVARGDLGVEI PAEKVCVAQMC I I SKCNVVG-----------KPVICATQMLESMT G--IMVARGDLGVEI PAEKVVVAQMC I I SKCNVAG----------KPVICATQMLESMT ----FTSGRYFHRS LNPEKLVAIAFSRI P PQYQKF----------QNPMSMLKRFYQVP ----FATADYYHRS LNPEKLVAVGFSXI PQQYQKF----------QNPLSMIKRFYELP ----FAKGHYFHRS LNSQKLVDVKFSGI P PHYKRF----------QNPVAVMERLYRLP

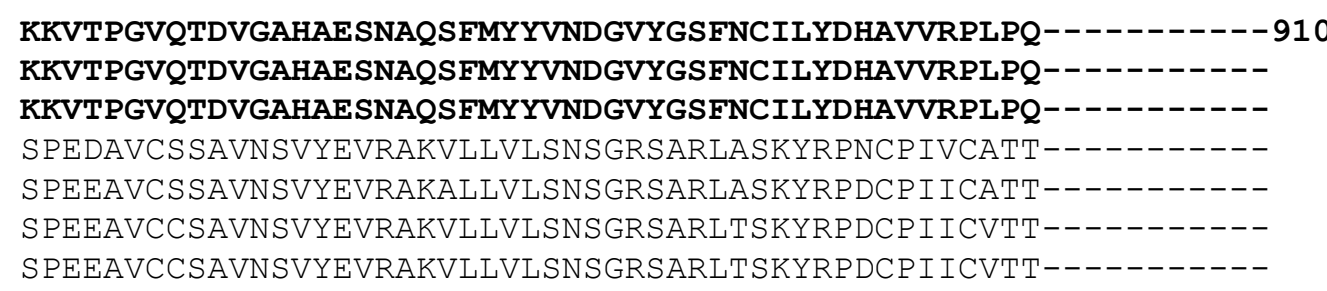

CPEEAVCSSAVASAFEVQAKAMLVLSNTGRSARLISKYRPNCPIICVTT----------- 910 CPEEAVCSSAVASAFEVQAKAMLVLSNTGRSARLISKYRPNCPI I CVTT-----------

REPI PNEKLYPSSVWGPTCDGLDQIVERYYLPEMQVGE------------WLLFEDMGA REPI PNEKLYPSSVWGPTCDGLDQIVERYYLPEMQVGE------------WLLFEDMGA REPIPNEKLYPSSVWGPTCDGLDQIVERYYLPEMQVGE------------WLLFEDMGA RMRTCRQLTITRSVEPVFYDAERYGDDESKEKRVQLG--------------VEWAKKRG RMRTCRQLTITRSVDAVFYDAERYGEDENKEKRVQLG--------------VDCAKKKG RMRTCRQLNVTRSVESVFYDAERCGADEDKENRVQLG------------- VESAKKKG RMRTCRQLNVTRSVESVFYDAERCGADEDKENRVQLG--------------VESAKKKG

Figure 18. Multiple sequence alignmentsamong the drug targets excluding Trypanosoma theileri protein 
Table 6. Percent identity and divergence of Cluster W alignment of drug targets

\begin{tabular}{|c|c|c|c|c|c|c|c|c|c|c|c|c|c|c|c|c|c|c|}
\hline & 1 & 2 & 3 & 4 & 5 & 6 & 7 & 8 & 9 & 10 & 11 & 12 & 13 & 14 & 15 & 16 & 17 & \\
\hline 1: XP_829429.1 & 100 & 99.78 & 99.76 & 18.72 & 17.82 & 17.82 & 17.52 & 15.81 & 17.22 & 16.92 & 17.03 & 17.03 & 14.58 & 14.5 & 13.33 & 10.98 & 18.22 & 1 \\
\hline 2: AAD02222.1 & 99.78 & 100 & 100 & 18.72 & 17.82 & 17.82 & 17.52 & 15.81 & 17.22 & 16.92 & 17.03 & 17.03 & 14.88 & 14.5 & 13.33 & 10.98 & 18.22 & 2 \\
\hline 3: AAA30219.1 & 99.76 & 100 & 100 & 19.23 & 16.5 & 16.5 & 16.18 & 13.47 & 16.18 & 15.53 & 16.79 & 16.79 & 15.19 & 14.41 & 13.53 & 10.98 & 18.6 & 3 \\
\hline 4: ABI96917.1 & 18.72 & 18.72 & 19.23 & 100 & 24.4 & 24.4 & 25.81 & 23.55 & 24.8 & 24.19 & 23.36 & 23.36 & 20.66 & 15.37 & 14.78 & 10.68 & 18.86 & 4 \\
\hline 5: XP_009309990.1 & 17.82 & 17.82 & 16.5 & 24.4 & 100 & 100 & 82.97 & 88.18 & 86.37 & 86.17 & 80.34 & 80.34 & 22.2 & 16.77 & 18.81 & 16.81 & 18.37 & 5 \\
\hline 6: KEG11772.1 & 17.82 & 17.82 & 16.5 & 24.4 & 100 & 100 & 82.97 & 88.18 & 86.37 & 86.17 & 80.34 & 80.34 & 22.2 & 16.77 & 18.81 & 16.81 & 18.37 & 6 \\
\hline 7: ССС 94421.1 & 17.52 & 17.52 & 16.18 & 25.81 & 82.97 & 82.97 & 100 & 91.21 & 82.16 & 82.36 & 86.89 & 86.89 & 23.17 & 17.07 & 18.51 & 16.38 & 19.59 & 7 \\
\hline 8: CCC52316.1 & 15.81 & 15.81 & 13.47 & 23.55 & 88.18 & 88.18 & 91.21 & 100 & 84.55 & 85.15 & 87.91 & 87.91 & 23.59 & 17.14 & 19.25 & 16.74 & 17.2 & 8 \\
\hline 9: ESL09806.1 & 17.22 & 17.22 & 16.18 & 24.8 & 86.37 & 86.37 & 82.16 & 84.55 & 100 & 89.58 & 80.34 & 80.34 & 22.44 & 17.38 & 20 & 17.67 & 15.92 & 9 \\
\hline 10: 3QV9_B & 16.92 & 16.92 & 15.53 & 24.19 & 86.17 & 86.17 & 82.36 & 85.15 & 89.58 & 100 & 80.63 & 80.63 & 21.71 & 17.07 & 18.81 & 17.24 & 16.33 & 10 \\
\hline 11: EAN78782.1 & 17.03 & 17.03 & 16.79 & 23.36 & 80.34 & 80.34 & 86.89 & 87.91 & 80.34 & 80.63 & 100 & 100 & 23.16 & 17.86 & 17.77 & 14.97 & 18.27 & 11 \\
\hline 12: XP_827894.1 & 17.03 & 17.03 & 16.79 & 23.36 & 80.34 & 80.34 & 86.89 & 87.91 & 80.34 & 80.63 & 100 & 100 & 23.16 & 17.86 & 17.77 & 14.97 & 18.27 & 12 \\
\hline 13: CAA44870.1 & 14.58 & 14.88 & 15.19 & 20.66 & 22.20 & 22.20 & 23.17 & 23.59 & 22.44 & 21.71 & 23.16 & 23.16 & 100 & 14.33 & 13.65 & 14.07 & 19.83 & 13 \\
\hline 14: XP_827904.1 & 14.5 & 14.5 & 14.41 & 15.37 & 16.77 & 16.77 & 17.07 & 17.14 & 17.38 & 17.07 & 17.86 & 17.86 & 14.33 & 100 & 59.64 & 63.52 & 13.58 & 14 \\
\hline 15: XP_009313274.1 & 13.33 & 13.33 & 13.53 & 14.78 & 18.81 & 18.81 & 18.51 & 19.25 & 20 & 18.81 & 17.77 & 17.77 & 13.65 & 59.64 & 100 & 69.45 & 11.93 & 15 \\
\hline 16: AEP82716.1 & 10.98 & 10.98 & 10.98 & 10.68 & 16.81 & 16.81 & 16.38 & 16.74 & 17.67 & 17.24 & 14.97 & 14.97 & 14.07 & 63.52 & 69.45 & 100 & 12.28 & ` 6 \\
\hline 17: XP_009316281.1 & 18.22 & 18.22 & 18.6 & 18.86 & 18.37 & 18.37 & 19.59 & 17.2 & 15.92 & 16.33 & 18.27 & 18.27 & 19.83 & 13.58 & 11.93 & 12.28 & 100 & 17 \\
\hline
\end{tabular}




\begin{tabular}{|l|ll}
\hline & Target protein & \multicolumn{1}{c}{ Species/strain } \\
\hline & Ornithine decarboxylase \\
Ornithine decarboxylase \\
Ornithine decarboxylase \\
Cathepsin L-like protein
\end{tabular}

TB: T.brucei, TG: T. grayi, TT: T. theileri, TC: T.cruzi, TR: T. rangeli, TV: T.vivax, TC: T.congolense

Figure 18. Phylogenetic tree following multiple sequence alignments showing relationships among common trypanocidal drug targets 


\section{Growth media and condition}

Trypanosoma theileri is one of the least studied trypanosomes although it is prevalent worldwide. This distribution may be due to the pathogenic nature of the parasite, which, compared to pathogenic ones, cannot cause a remarkable loss of production and productivity in livestock. However, nowadays researchers are focusing on T. theileri since it has been used as a setup and new tool for trypanosomatid-based delivery (Mott et al., 2011) for the treatment of pathogenic trypanosome and other hemoparasites affecting livestock and humans. Nevertheless, due to its low parasitemic nature, it is rarely detected by direct smear microscopy. In view of this, Verloo et al. (2000) developed a kit called KIVI as an excellent tool for isolating $T$. Theileri which they found successful.

There are a number of media that must be cultured for both epimastigote and trypanosome's blood flow stages. For the blood flow stages of T. theileri (Trypomastigotes), RPMI medium 1640 with $10 \%$ FCS, supplemented with murine spleen cells as a feeder layer, was used (Verloo et al., 2000). In addition, it could be cultured in tissue culture fluid NCTC-109 (Splitter and Soulsby, 1967), 50\% HMI-9 medium (Hirumi and Hirumi, 1989) supplemented with 20\% FCS, 10\% Serum, and 50\% MDBK-conditioned media (Mott et al., 2011).

In the present study, it was possible to grow T. theileri epimastigotes in SDM 79 with $10 \%$ FCS at $26^{\circ} \mathrm{C}$ without $\mathrm{CO}_{2}$ betweenfour media tested (Figure 2). Under similar growth conditions, Wink (1979) cultured T. Theileri epimastigotes at $25^{\circ} \mathrm{C}$ with $10 \% \mathrm{FCS}$, but with different growth media, Glossina Cell culture Medium (GCM). Moreover, in the second growth condition (at $37^{\circ} \mathrm{C}$ with $5 \% \mathrm{CO}_{2}$ ) there was slight growth of T. theileri epimastigotes in RPMI 1640 (Figure 3), which was confirmed by Verloo et al. (2000), who could culture T. theileri with RPMI 1640. However, the growth of $T$. theileri epimastigote in RPMI 1640 at $26^{\circ} \mathrm{C}$ with $\mathrm{CO}_{2}$ was less than the time cultivated at $26^{\circ} \mathrm{C}$ without $\mathrm{CO}_{2}$ (Figure 2) in the present study. This could be due to the reluctance to use PMI conditioning since they used a feeder layer of murine spleen cells. In addition, Verloo et al. (2000) cultured the blood flow stage that was directly isolated from the blood.

\section{Growth pattern and doubling time}

The culture of $T$. theileri in eight different tissue culture flasks showed maximum growth on the sixth day during the eight experiments, except for the seventh experiment on the seventh day. On the other hand, as can be seen in Figure 3 , the log phase starts clearly from the third day. This indicated that the logarithmic phase of growth was started from the third to the sixth day and from the third to the seventh day for the seventh experiment. The maximum number of cells that could be grown among the eight flasks was estimated to be $1.7 \times 10^{7}$ cells $/ \mathrm{mL}$ (Experiment 2). Hence, the logarithmic phase extended from $3.2 \times 10^{4}$ cells $/ \mathrm{mL}$, which was on the third day of the experiment. Second, to the highest $1.3 \times 10^{7}$ cells $/ \mathrm{mL}$ from the same flask on the sixth day except for Experiment seven. The doubling time in the logarithmic growth phase was estimated to range from 13.43 to 19.0 hours with an average estimate of 17.43 hours (0.73 day) in eight experiments. The doubling time of the present study is slightly higher than the doubling time of T. theileri reported by Wink (1979) with a doubling time of 10-14 hours. However, the growth pattern of T. theileri is 2.5 times higher than the doubling time of T.b.bruceias described by Sykes and Avery (2009) and Melissa et al. (2009).

The doubling time could indicate that $T$. theileri grows more slowly than other similar reports. The slow growth rate could be due to different media types and growing conditions. It is in a sense that, if the parasite has got a favorable growth environment, they may have the opportunity to divide within a short period. Furthermore, the slower growth of $T$. theileri compared to the growth of other pathogenic Trypanosomesmay be linked to the factors that could make the parasite a pathogen. This means that the longer replication time and the lower parasitemic features can naturally cause the least amount of anemia. The serious losses from pathogenic trypanosomes are principally due to anemia. Furthermore, the lower detection level in the blood can limit the distribution of the parasite to different visceral organs and haemopoietic tissues, such as the spleen. Moreover, virulent trypanosomes have a shorter incubation period than pathogen ones (Magona et al., 2008). The longer the doubling time which was needed in the present study, can be related to this point. The same applies to the study by Böse et al. (1987), who reported that after identifying the stages of infection of $T$. theileri in the gut and feces of tabanids, it could be determined that the minimum prepatent period of around four days in infected cattle despite no apparent signs of disease were detected.

\section{Resazurin assay}

The epimastigote $\left(5.2 \times 10^{5} / \mathrm{mL}\right.$ to $\left.8.5 \times 10^{6} / \mathrm{mL}\right)$ was grown in a microtiter plate for three different concentrations of Resazurin. Initially, there was a lower fluorescence signal throughout the three Resazurin concentrations. However, it increased significantly from $1.2 \times 10^{6}$ cells $/ \mathrm{ml}$ and reached the highest fluorescence signal detection at $3.5 \times 10^{6}$ cells $/ \mathrm{mL}$ following the seventh hour of incubation with Resazurin. It indicated that there was a positively correlated $(\mathrm{r}=0.7517$ $0.9252 ; \mathrm{p}<0.05)$ fluorescence signal with an increase in cell density and Resazurin concentrations. 
On the other hand, there was a positive correlation $(r=0.8297 ; \mathrm{p}<0.05)$ among fluorescence signals as a result of $2.4 \mathrm{mM}$ Resazurin than the other two concentrations with an increase in incubation time (Figure 8 ) until 7 hours using an optimal $1.2 \times 10^{6}$ cells $/ \mathrm{mL}$ of cell density. The fluorescence decreased dramatically after the seventh hour of incubation with Resazurin (Figure 7). It is in agreement with a study by Tana et al. (2012) who reported that Resazurin was reduced linearly after three to four hours of incubation with $25 \mathrm{mg} / \mathrm{mL}(20 \mu \mathrm{L} /$ well $)$ Resazurin though it was done on $T$. brucei. They also reported that the maximum fluorescence was recorded in the range of $2-5 \times 10^{6}$ cell/mL which was almost similar to the optimal cell density found for higher fluorescence $\left(1.2-3.5 \times 10^{6}\right.$ cells $\left./ \mathrm{mL}\right)$ with $2.4 \mathrm{Mm}$ Resazurin. There was a very high and linear correlation $(\mathrm{r}=0.9876)$ observed in the fluorescence signal of the parasite in the range of $1.3 \times$ $10^{6}$ to $5.3 \times 10^{6}$ cells $/ \mathrm{ml}$ upon incubating with $2.4 \mathrm{mM}$ Resazurin for 7 hours at $26^{\circ} \mathrm{C}$. It is slightly higher than the incubation time used for fluorescence assay for $T$. cruzi which was 5 hours as reported by Miriam et al. (2006). Similarly, according to Tana et al. (2012), there was a linear reduction of Resazurin after a 3-4 hours period of contact time since there might be a saturation of the fluorescence at such high parasite densities. A report by Miriam et al. (2006) also showed the highest concentrations of Resazurin $(3 \mathrm{mM})$ among the Resazurin concentrations they tested (0.5 to 3 $\mathrm{mM}$ ), showed the highest Resazurin reduction. The same is true from our experiment since the highest Resazurin concentration $(2.4 \mathrm{mM})$ showed a similar pattern. It may be due to the fact that whenever we use the lowest concentration of Resazurin, the Resazurin (blue) can be converted to a more fluorescent resorufin(pink) immediately within a short time. Then, if it was allowed for a long incubation time, the resorufin which is the fluorescent one will be converted to a non-fluorescent stage finally. It shows an imbalance between the highest numbers of cells with the lowest concentration of Resazurin used. Due to this, maybe the highest concentration showed a significant correlation in the magnitude of fluorescent signal with an increase in cell density and incubation time.

\section{Drug sensitivity}

The Resazurin assay enables the measurement of parasite viability as an indicator of the ability to recover from compound effects (Nare et al., 2010; Tana et al., 2012). By using the optimization conditions we established for cell density and Resazurin concentration, the Resazurin-lead assay was applied to assess the susceptibility of $T$. theileri epimastigotes to Pentamidine (Sigma, 1-100 ng/mL). As a consequence, a negatively correlated $(\mathrm{r}=-0.8826)$ and statistically significant $(\mathrm{p}<0.05)$ difference were observed between the reduction in fluorescence signal and an increase in pentamidine concentration predominantly in the highest drug concentration. A study was done on T.b.brucei by Tana et al. (2012) also indicated a similar response of the parasite following 72 hours of incubation with Pentamidine which result in a dramatic reduction of Resazurin signal. The viability percentage was determined by comparing both microscopic counting which is anti-epimastigotes $(\% \mathrm{AE})$ and the resazurin assay with Pentamidine $(1-100 \mathrm{ng} / \mathrm{mL})$. IC 50 values of $9.25 \mathrm{ng} / \mathrm{mL}$ and $16.29 \mathrm{ng} / \mathrm{mL}$ were found by using Resazurin $(\mathrm{r}=-0.957, \mathrm{p}<0.05)$ and microscopic counting ( $\mathrm{r}$ $=0.90, \mathrm{p}<0.05)$ respectively. These two tests showed roughly similar outcomes though Resazurin assay was more preferable since it has relatively lower $\mathrm{IC}_{50}$ (Figure 11). Furthermore, it allowed screening a large sample size as far as microscopic counting is time-consuming. It was in agreement with the report by Miriam et al. (2006) and Sykes and Avery (2009) mentioning that Resazurin was preferable to test the viability of T.b. brucei for Pentamidine and Suramin. The $\mathrm{IC}_{50}$ value was higher than the reports by Sykes and Avery (2009) and Tana et al. (2012), who reported 5ng/mL and $40 \mathrm{nM}$, respectively for T.brueci.

\section{Experimental infection of calves}

During the experimental infection of the present study, the identification of parasites both in Giemsa stained slides and through culturing the PBMC and the buffy coat in RPMI 1640 and HMI 9 medium was unsuccessful. However, a similar method of experimental infection was followed by Mott et al. (2011). The problems could be, first, the parasite could die in transit prior to inoculation since the farm was a few kilometers away from the laboratory where the parasite was cultured. Secondly, it might be due to the time it took for replication to happen. According to the doubling time calculated during the in vitro culture, they needed 13.43 to 19 hours. Third, based on the amount of the parasite, the calf was inoculated between five and nine ml. Finally, maybe another co-founding factor has not yet been realized. Nevertheless, a similar study was done by Mott et al. (2011) after experimental infection. However, they extracted DNA directly from whole blood samples than growing the parasite after identification from buffy coat and/or PBMC since it's rarely detected due to the low level of parasitemia. However, the focus of the present study was on the culturing of the blood-streaming form in mass after isolating from the blood for further proteomic studies; to compare the epimastigote and trypomastigotes proteomics.

\section{PCR confirmation of Trypanosoma theileri}

Trypanosoma theileri could be differentiated from other trypanosomes through a species-specific primer (Tth625) as described by Rodrigues et al. (2003), PCR-amplified spliced-leader transcript, 18S ribosomal DNA, and internal transcribed spacer of ribosomal genes (ITS gene, Geysen et al., 2003). In the present study, the results obtained by PCR 
and agarose gel electrophoresis based on Species-specific primers confirmed a 465 bp amplification product which was comparable with 450 bp DNA fragment (Tth625 fragment) by Rodrigues et al. (2003)and 472 bp by Lee et al. (2013). For the second amplification for the $18 \mathrm{~S}$ rDNA sequence of $T$. theileri, a band with a size of $730 \mathrm{bp}$ was detected, which was almost expected to be $722 \mathrm{bp}$, as reported by Geysen et al. (2003).

\section{In silico analysis}

The BLAST and Clustal W alignment were done both at nucleotide (DNA) and protein level with target sequences of common anti-trypanosome drugs. Following a BLAST and Cluster W alignment using these common drug targets, there was only one slight homogeneity (75\%) gene (CATL gene) which was found in both T.grayi (XM_009318006.1) and HQ664735.1 of $T$. theileri isolate in common. On the other hand, among the drug targets only, excluding T. theileri genome; they had a very high identity especially among XM_824336.1 (100\%), J02771.1 (99\%), and AF042286 (99\%) which entirely indicated Ornithine decarboxylase gene inT.brucei. The phylogenetic tree and ClusterW alignment also showed these relationships. Lee et al. (2013)have got the homology of their isolate (TWTth1) from Taiwan with isolates by Rodrigues et al. (2003), Gene Bank Accession No: AF537201 (99.5\%) and AF537202 (98.8\%) from Brazil. They did the comparison based on T. theileri DNA. In addition, based on the full-length 18S rDNA sequence amplicon of their isolate, they found $100 \%$ identity with AB007814.1. Based on ITS sequences, Lee et al.(2013)reported that there was a similarity amongAB007814 (100\%), AY773707 (97.3\%), and AY773708 (98.0\%) which are Japanese and Brazilian isolates.

At the protein level, there was almost no similarity of these drug targets with the proteins found in the NCBI database except a slight similarity with hypothetical T. theileri proteins (TM35). However, among the drug targets, a prominent homology was detected among XP_829429.1(100\%), AAD02222.1, and AAA30219.1 which indicated ornithine decarboxylase protein as was obtained after analyzing at DNA level in the current study. The MSA and the phylogenetic trees witnessed the homology of these sequences.

Accordingly, BLAST was used in the current study and aligned only with partial and hypothetical sequences of the T. theileri. However, there were homologies of sequences from anti-trypanosome drug targets specifically for Ornithine decarboxylase from T.brucei. Similarly, Rodrigues et al. (2003) reported that T. theileri and 'T. brucei clade' trypanosomes shared artiodactyl host species with overlapping distributions and commonly bovids carrying mixed trypanosome infection in the field.

\section{CONCLUSIONS}

In the present study, T. theileri was successfully cultured in vitro in SDM 79 at $26^{\circ} \mathrm{C}$. The growth pattern, viability, and response to pentamidine were assessed by Resazurin assay. T. theileri parasite took a longer time to double the population, compared to other trypanosomes. Moreover, the Resazurin assay using pentamidine was deployed as the reference drug to confirm the effectiveness of this assay technique. Consequently, it could be possible to use such a sensitive and inexpensive assay for high-throughput screening of anti-trypanosome compounds. On the other hand, after extraction of the DNA by the PhenolChloroform protocol from cultured $T$. theileri, the parasite was confirmed using PCR amplification by species-specific primers.

Furthermore, the BLAST and MSA were performed with common anti-trypanosome target sequences. Subsequently, in contrast to the anti-trypanosome targets of pathogenic trypanosomes, significant similarity at both the DNA and protein level with T. theileri was detected. However, some similarities to hypothetical. theileri proteins (TM35) were observed. Both at DNA and protein level, significant homologyamongXP_829429.1, AAD02222.1, and AAA30219.1 were detected which all referred to ornithine decarboxylase protein in T.brucei. The lack of homology in $T$. theileri might be due to the lack of a complete genome sequence. Finally, whole-genome and transcriptome analyses using $T$. theileri can reveal the phylogenetic relationship between $T$. theileri and other pathogenic trypanosomes, which can be used as a tool in the development of new therapeutic drugs for the treatment of the pathogenic trypanosome.

Based on the above conclusions, the following recommendations are put forward. The present study provides baseline data for the next research on the parasite. In the case of experimental infection, it is better to infect the test animal as soon as possible, while the parasite could soon die if transported with PBS. Long and continuous blood sampling should be performed after experimental infection. In the present study, only two consecutive weeks were checked after each infection. There is a chance that the parasite may not be immediately naturally isolated due to a low level of parasitemia. Hence, most of the isolation of $T$. theileri from natural infection was not purposively confirmed. Rather, it was found in an unexpected time. It can be isolated while researchers pursue other goals. For example, the total leukocyte and differential count, and PCV are examined during the macrophage culture while the Bovine Leukemia Virus(BLV) is examined from lymphocyte cultures of cows infected with it. It is better to use a reader with higher fluorescence to get a higher magnitude of the fluorescence signal. Better to use more than two drugs for treatment so that the drug sensitivity assay is representative and comparable. 


\section{DECLARATIONS}

\section{Authors' contribution}

Tewodros Fentahun contributed to data collection, lab activities, and a write-up of the manuscript. Jan Paeshuyse was involved in data analysis. Both authors confirmed the final revised manuscript.

\section{Competing interests}

The authors have no conflicts of interest.

\section{Acknowledgments}

The authors would like to thank VLIR OUS, Katholic University of Leuven, and Institute of Tropical Medicine, Belgium, for their collaboration in the preparation of this research.

\section{Ethical considerations}

Ethical issues (including plagiarism, consent to publish, misconduct, data fabrication and/or falsification, double publication and/or submission, and redundancy) have been checked by the authors.

\section{REFERENCES}

Aerts D, Truc P,PenchenierL, Claes Y, and Ray Le(1992). A kit for in vitro isolation of trypanosomes in the field: first trial with sleeping sickness patients in the Congo Republic.Transaction of the Royal Society of Tropical Medicine and Hygiene, 86: 394395. Available at:http://www.sleeping-sickness.ird.fr/pdf/35977.pdf

Alonso-Padilla Jand Rodríguez A (2014). High Throughput Screening for AntiTrypanosoma cruzi Drug Discovery. PLoS Neglected Tropical Diseases, 8(12): e3259. DOI: https://doi.org/10.1371/journal.pntd.0003259

Amaro RE, Schnaufer A, Interthal H, Hol W, Stuart KD, and McCammon JA (2008). Discovery of drug-like inhibitors of an essential RNA-editing ligase in Trypanosoma brucei. Proceedings of the National Academy of Sciences of the United States of America, 105(45): 17278-83. DOI: https://doi.org/10.1073/pnas.0805820105.

Böse R, Friedhoff KT, and Olbrich S (1987). Transmission of Megatrypanum trypanosomes to Cervus dama by Tabanidae. Journal of Protozoology, 34: 110-113. DOI: https://doi.org/10.1111/j.1550-7408.1987.tb03143.x

Braun U, Rogg E, Walser M, Nehrbass D, Guscetti F, Mathis A, Deplazes P(2002) Trypanosoma theileri in the cerebrospinal fluid and brain of a heifer with suppurative meningoencephalitis. VeterinaryRecords, 150: 18-19. Available at:https://europepmc.org/article/med/11817859

Ekins S, Mestres J, and Testa B (2007). In silico pharmacology for drug discovery: methods for virtual ligand screening and profiling. British Journal of Pharmacology, 152:9-20. DOI: https://doi.org/10.1038/sj.bjp.0707305.

Fatumo S, Adebiyi M A, anddebiyi E (2013). In silico models for drug discovery. (M. Lill, Edition), InSilico Models for Drug Discovery. DOI: https://doi.org/10.1007/978-1-62703-342-8.

Geysen D, Delespaux V, and Geerts S (2003). PCR-RFLP using Ssu-rDNA amplification as an easy method for species-specific diagnosis of Trypanosoma species in cattle. Veterinary Parasitology, 110: 171-180. DOI: https://doi.org/10.1016/S03044017(02)00313-8.

Hirumi H and Hirumi K (1989). Continuous cultivation of Trypanosoma brucei bloodstream forms in a medium containing a low concentration of serum protein without feeder cell layers. Journal of Parasitology, 75: 985-989. DOI:https://doi.org/10.2307/3282883

Latif AA, Bakheit M a, Mohamed AE, and Zweygarth E (2004). High infection rates of the tick Hyalomma anatolicum anatolicum with Trypanosoma theileri. The Onderstepoort Journal of Veterinary Research, 71(4): 251-256. Available at:https://journals.co.za/content/opvet/71/4/EJC86189

Lee YF, Cheng CC, Chen JS, Lin NN, Hung YW, Wang JM, and Chiu YT (2013). Evidence of intracellular stages in Trypanosoma (Megatrypanum) theileri in non-phagocytic mammalian cells. Veterinary Parasitology, 191(3-4): 228-239. DOI: https://doi.org/10.1016/j.vetpar.2012.08.027.

Lukes J (2009). Trypanosoma Gruby 1843. Version 02 January 2009 (under construction). Available at: http://tolweb.org/Trypanosoma/98034/2009.01.02\%20in\%20The\%20Tree\%20of\%20Life\%20Web

Magona JW, Walubengo J, and Odimin JT(2008). Acute haemorrhagic syndrome of bovine trypanosomosis in Uganda. Acta Tropica, 107: 186-191. DOI: https://doi.org/10.1016/j.actatropica.2008.05.019.

Melissa S, Avery T, and Vicky C(2009). A luciferase based viability assay for ATP detection in 384-well format for high throughput whole cell screening of Trypanosoma brucei brucei bloodstream form strain 427. Parasites and Vectors, 2(1): 54. DOI: https://doi:10.1186/1756-3305-2-54.

Miriam R, Celeste V, Jose Antonio E, and Alicia B(2006). Development of resazurin microtiter assay for drug testing of Trypanosoma cruzi epimastigotes. Parasitology Research, 99(2): 103-107. DOI: https://:doi:10.1007/s00436-006-0126-y.

Mott GA, Wilson R, Fernando A, Robinson A, MacGregor P, Kennedy D, and Matthews KR (2011). Targeting cattle-borne zoonoses and cattle pathogens using a novel trypanosomatid-based delivery system. PLoS Pathogens, 7(10): 1-9. DOI:https://doi.org/10.1371/journal.ppat.1002340.

Murray M, Murray P K, and McIntyre W I(1977). An improved parasitological technique for the diagnosis of African trypanosomiasis.Transactions of The Royal Society of Tropical Medicine and Hygiene, 71(4): 325-326. DOI: 
Nare B, Wring S, Bacchi C, Beaudet B, Bowling T, Brun R, Chen D, Ding C, Freund Y, Gaukel E et al. (2010). Discovery of novel orally bioavailable oxaborole 6-carboxamides that demonstrate cure in a murine model of late-stage central nervous system African trypanosomiasis. Antimicrobial Agents and Chemotherapy, 54: 4379-4388. DOI: https://DOI: 10.1128/AAC.00498-10.

Rodrigues AC, Campaner M, Takata CSA, Dell' Porto A, Milder RV, Takeda GF, and Teixeira MMG (2003). Brazilian isolates of Trypanosoma (Megatrypanum) theileri: Diagnosis and differentiation of isolates from cattle and water buffalo based on biological characteristics and randomly amplified DNA sequences. Veterinary Parasitology, 116(3): 185-207. DOI: https://doi.org/10.1016/S0304-4017(03)00236-X.

Shapiro Ta, and Englund PT (1990). Selective cleavage of kinetoplast DNA minicircles promoted by antitrypanosomal drugs. Proceedings of the National Academy of Sciences of the United States of America, 87(3): 950-954. DOI: https://doi.org/10.1073/pnas.87.3.950.

Shastri UV, and Deshpande PD (1981). Hyalomma anatolicum anatolicum (Koch, 1844) as a possible vector for transmission of Trypanosoma theileri, Laveran, 1902 in cattle. Veterinary Parasitology, 9(2): 151-155. DOI: https://doi.org/10.1016/03044017(81)90034-0.

Splitter EJ, and Soulsby EJ (1967). Isolation and continuous cultivation of Trypanosoma theileri inmedia containing tissue culture fluids. Experimental Parasitology, 21(2): 137-148. Available at:http://www.ncbi.nlm.nih.gov/pubmed/4169719.

Sykes M, and Avery V (2009). Development of an alamar Blue ${ }^{\mathrm{TM}}$ viability assay in 384-well format for high throughput whole cell screening of Trypanosoma brucei bruceibloodstream form strain 427.The American Journal of Tropical Medicine and Hygiene, 81(4): 665-674. DOI: https://doi.org/10.4269/ajtmh.2009.09-0015

Tana Bowling, Luke Mercer,Robert Don,Robert Jacobs, and Bakel Narea (2012). Application of a resazurin-based high-throughput screening assay for the identification and progression of new treatments for human African trypanosomiasis. International Journal of Parasitology and Drugs Drug Resistance, 2: 262-270. DOI: https://doi.org/10.1016/j.ijpddr.2012.02.002.

Verloo D, Brandt J, Van Meirvenne N, and Büscher P (2000). Comparative in vitro isolation of Trypanosoma theileri from cattle in Belgium. Veterinary Parasitology, 89(1-2): 129-132. DOI: https://doi.org/10.1016/S0304-4017(00)00191-6.

Wink M (1979). Trypanosoma theileri: In vitro cultivation in tsetse fly and vertebrate cell culture systems.International Journal for Parasitology, 9(6): 585-589. DOI:https://doi.org/10.1016/0020-7519(79)90016-X 